\title{
Light absorption and partitioning in Arctic Ocean surface waters: impact of multiyear ice melting
}

\author{
S. Bélanger ${ }^{1}$, S. A. Cizmeli ${ }^{1,2}$, J. Ehn ${ }^{3}$, A. Matsuoka ${ }^{4}$, D. Doxaran ${ }^{5}$, S. Hooker ${ }^{6}$, and M. Babin ${ }^{4}$ \\ ${ }^{1}$ Université du Québec à Rimouski, Département de Biologie, Chimie et Géographie and BORÉAS, 300 allée des Ursulines, \\ Rimouski, Québec G5L 3A1, Canada \\ ${ }^{2}$ Arctus inc., 300 allée des Ursulines, Rimouski, Québec G5L 3A1, Canada \\ ${ }^{3}$ University of Manitoba, Center for Earth Observation Science, 337 Wallace Building, Winnipeg, MB, R3T 2N2, Canada \\ ${ }^{4}$ Takuvik Joint International Laboratory (CNRS \& ULaval), Département de Biologie, Québec-Océan and Arcticnet, \\ Université Laval, Pavillon Alexandre-Vachon, 1045, av. de la Médecine, Québec (Québec), G1V 0A6, Canada \\ ${ }^{5}$ CNRS, Université Pierre et Marie Curie-Paris 6, UMR 7093, Laboratoire dOcéanographie de Villefranche/Mer, 06230 \\ Villefranche-sur-Mer, France \\ ${ }^{6}$ NASA Goddard Space Flight Center, Ocean Ecology Laboratory, Greenbelt, Maryland 20771, USA
}

Correspondence to: S. Bélanger(simon_belanger@uqar.ca)

Received: 7 January 2013 - Published in Biogeosciences Discuss.: 21 March 2013

Revised: 19 June 2013 - Accepted: 1 September 2013 - Published: 11 October 2013

\begin{abstract}
Ice melting in the Arctic Ocean exposes the surface water to more radiative energy with poorly understood effects on photo-biogeochemical processes and heat deposition in the upper ocean. In August 2009, we documented the vertical variability of light absorbing components at 37 stations located in the southeastern Beaufort Sea including both Mackenzie River-influenced waters and polar mixed layer waters. We found that melting multiyear ice released significant amount of non-algal particulates (NAP) near the sea surface relative to subsurface waters. NAP absorption coefficients at $440 \mathrm{~nm}\left(a_{\mathrm{NAP}}(440)\right)$ immediately below the sea surface were on average 3 -fold (up to 10-fold) higher compared to subsurface values measured at $2-3 \mathrm{~m}$ depth. The impact of this unusual feature on the light transmission and remote sensing reflectance $\left(R_{\mathrm{rs}}\right)$ was further examined using a radiative transfer model. A 10-fold particle enrichment homogeneously distributed in the first meter of the water column slightly reduced photosynthetically available and usable radiation (PAR and PUR) by $\sim 6$ and $\sim 8 \%$, respectively, relative to a fully homogenous water column with low particle concentration. In terms of $R_{\mathrm{rs}}$, the particle enrichment significantly flattered the spectrum by reducing the $R_{\mathrm{rs}}$ by up to $20 \%$ in the blue-green spectral region $(400-550 \mathrm{~nm})$. These results highlight the impact of meltwater on the concentration of particles at sea surface, and the need for consider-
\end{abstract}

ing non-uniform vertical distribution of particles in such systems when interpreting remotely sensed ocean color. Spectral slope of $a_{\text {NAP }}$ spectra calculated in the UV (ultraviolet) domain decreased with depth suggesting that this parameter is sensitive to detritus composition and/or diagenesis state (e.g., POM (particulate organic matter) photobleaching).

\section{Introduction}

Most of the solar irradiance penetrating the ocean ends up being absorbed; the remaining small percentage is backscattered to the atmosphere. Changes in the depth at which light penetrates in the water column can be explained to a large extent by variations in the absorption and backscattering coefficients, two inherent optical properties of the medium. Pure seawater, phytoplankton, colored dissolved organic matter (CDOM) and non-algal particles (NAP; detritus) are the major classes of optically significant substances most commonly used to partition absorption (Babin et al., 2003). Each of these constituents absorbs a fraction of the incident light and converts most of it into heat. Thus, the concentration and distribution of the optically active constituents plays an important role in the vertical heating rates of the upper ocean (Morel and Antoine, 1994; Hill, 2008; Pegau, 2002). 
A small fraction $(<1-2 \%)$ of the absorbed radiative energy supports photochemical reactions that play a pivotal role in the ocean's primary production, biogeochemical cycling of several elements $(\mathrm{C}, \mathrm{N}, \mathrm{P}, \mathrm{Fe}, \mathrm{Cu})$ and in the functioning of marine ecosystems. Light absorbed by phytoplankton pigments fuels photosynthesis of organic matter (e.g., Morel, 1991), while the highly energetic light absorbed by CDOM contributes to its photomineralization and to the photoproduction of various key inorganic species (Mopper and Keiber, 2002). Until recently, little was known about the photoreactivity of particulate organic matter (POM), but it now appears as a non-negligible actor in the photochemical activity taking place in the upper photic layer (Song et al., 2013; Xie and Zafiriou, 2009). A detailed knowledge of seawater absorption becomes a prerequisite if one needs to model photochemical processes, which in turn depend on the contribution of each component to the absorbed photon budget.

The Arctic Ocean is losing its multiyear ice cover at a rate reaching as much as $0.154 \pm 0.038$ million $\mathrm{km}^{2} \mathrm{yr}^{-1}$ since 1999 (Stroeve et al., 2012). The loss of sea ice is impacting all aspects of the system, from the physics to the ecology: storage of freshwater (Giles et al., 2012), sea ice albedo feedback (Flanner et al., 2011; Perovich et al., 2007), increasing sea surface temperature (Comiso et al., 2003), increasing cloudiness (Palm et al., 2010); increasing gas exchanges (Bates and Mathis, 2009), nutrients cycling (Tremblay and Gagnon, 2009), marine microbes (Li et al., 2009), etc. The loss of sea ice allows more solar radiation to penetrate into the ocean, stimulating photochemical processes such as primary production (Arrigo and van Dijken, 2011; Bélanger et al., 2013) and CDOM photooxidation (Bélanger et al., 2006). Less is known about the impact of multiyear ice melting on the upper ocean's optical properties themselves and its effect on light transmission and remote sensing determination of optically significant constituents.

Optical properties of the southeastern Beaufort Sea were measured in late summer 2009 as part of the MALINA program. Light absorbing components in this region have been previously investigated. For example, Matsuoka et al. (2009) and Brunelle et al. (2012) studied the variability in phytoplankton pigments absorption, while Bélanger et al. (2008, 2006) and Matsuoka et al. (2012) focused on the CDOM components. Except for the latter study, previous studies have had relatively poor spatial and vertical sampling resolutions. The MALINA sampling strategy allowed us to get a snapshot at relatively high vertical and horizontal resolution along and across the full extent of the Mackenzie shelf (Fig. 1). The sea surface during the survey was heavily influenced by sea ice melting, providing an opportunity to examine its impact on the upper ocean's absorption properties.

In this study we present an extensive data set in terms of light absorption coefficients of phytoplankton, NAP and CDOM. Specifically, our objectives are (1) to document the horizontal and vertical distribution of each absorbing component and their individual contribution to the total non-water

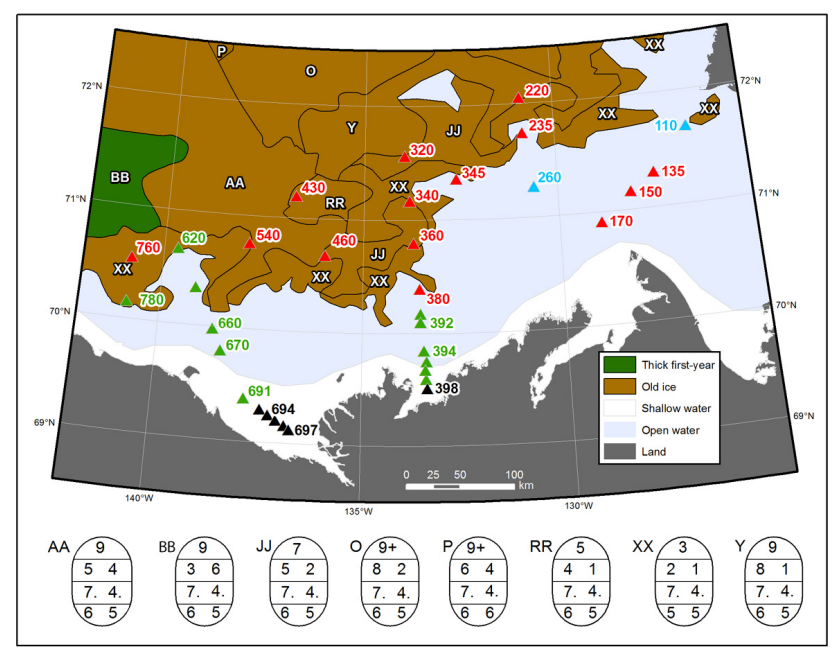

Fig. 1. Location of stations visited during the MALINA cruise on top of the sea ice chart of the Canadian Ice Service of 10 August 2009. Colored symbols correspond to the type of surface water masses as defined in Fig. 2. Ice information is presented in the Egg Code format and color-coded using the WMO Standard. The upper line shows the total sea ice concentration reported in tenths, while the second line is the concentration for the partial concentrations of different ice thicknesses. The third line stands for the stage of ice development (e.g., 7, old ice; 4, thick first year ice $(>120 \mathrm{~cm})$. The bottom line stands for the size of ice floes (e.g., 4 , medium floe (100-500 m); 5, big floe (500-2000 m); 6, vast floe (2-10 km)

absorption; (2) to examine the impact of multiyear ice melting on the optical properties of the upper ocean, and in particular on NAP distribution; and (3) to investigate the nature of NAP based on their optical properties. In Sect. 2 we describe the methods used to collect water samples and their immediate analysis onboard the ship. The Hydrolight radiative transfer model was used to examine the partitioning of incident solar radiation in the upper $10 \mathrm{~m}$ of the ice-free water column. In Sect. 3 our results are shown and discussed. These stations were located along transects that extended from the Mackenzie shelf to ice-covered Canada Basin waters (Fig. 1). Conclusions are presented in Sect. 4.

\section{Material and methods}

\subsection{Sampling strategy}

Data were collected from 30 July to 27 August 2009 aboard the Canadian icebreaker CCGSAmundsen and 37 stations were visited (Fig. 1). Temperature and salinity profiles were obtained using a SBE-911 plus (SeaBird) conductivitytemperature-depth (CTD) probe. Discrete water samples were collected at 6 to 10 depths using Niskin bottles mounted on a rosette sampler. To avoid perturbations from the ship's shadow on radiometric measurements, a so-called barge (i.e., 
a $12 \mathrm{~m}$ self propelled flat deck vessel) and/or a zodiac were also deployed at 32 stations to perform in-water optical measurements and to collect near-surface water samples. The barge generally stayed nearby the icebreaker $(<1 \mathrm{~km})$ and its sampling was conducted within a few hours of the ship-based CTD rosette deployment. Optical instrument packages were deployed from the barge to obtain vertical profiles of inherent optical properties (IOPs) and apparent optical properties (AOPs) (Hooker et al., 2013; Doxaran et al., 2012). Hooker et al. (2013) report diffuse attenuation coefficients $\left(K_{d}\right)$ and remote sensing reflectance $\left(R_{\mathrm{rS}}\right)$ that were calculated using radiance and irradiance measurements made using a Compact Optical Profiling System (C-OPS, Biospherical).

On the barge, water samples were collected using a $20 \mathrm{~L}$ clean carboy submerged manually below the sea surface at $\sim 10 \mathrm{~cm}$ depth in order to avoid the sea surface micro layer. This was checked twice at stations 430 and 460 where water samples were collected using (1) the carboy as usual, (2) a hand-held Kemmerer bottle, which is particularly adapted for a precise sampling near the surface, closed horizontally at $10 \mathrm{~cm}$ depth and (3) a Kemmerer bottle deployed manually and closed at $0.5,1,1.5,2$ and $3 \mathrm{~m}$ depths. The results of these experiments near the melting multiyear ice are reported in Sect. 3.3.

\subsection{Absorption measurements}

Measurements of the absorption coefficients of suspended particles were made using a filter-pad technique modified from Röttgers and Gehnke (2012). A known volume of seawater was filtered through $25 \mathrm{~mm}$ Whatman GF/F (glassfiber filters) shortly after sampling $(<3 \mathrm{~h})$. Each filter was then placed in the center of a $150 \mathrm{~mm}$ integrating sphere equipped with a handmade Spectralon filter holder (see Röttgers and Gehnke, 2012, for technical details). The spectral optical density $(\mathrm{OD}(\lambda))$ of the particles retained on the filter was then measured using a PerkinElmer Lambda-19 spectrophotometer, from $300-800 \mathrm{~nm}$ at $1 \mathrm{~nm}$ resolution. The $\mathrm{OD}(\lambda)$ was converted to the spectral particulate absorption coefficient, $a_{\mathrm{p}}(\lambda)\left(\mathrm{m}^{-1}\right)$, using Eq. (1),

$a_{\mathrm{p}}(\lambda)=2.303 \times\left(\frac{A}{V}\right) \times\left(\frac{\mathrm{OD}(\lambda)-\mathrm{OD}_{\text {blank }}(\lambda)}{\beta(\lambda)}\right)$,

where OD $_{\text {blank }}$ is the optical density of a blank filter soaked in filtered seawater, $A$ the clearance area of the particles on the filter $\left(\mathrm{m}^{2}\right), V$ the volume of sample water filtered $\left(\mathrm{m}^{3}\right)$, and $\beta$ the path length amplification factor. A relationship between $\beta$ and OD (Eq. 2) determined experimentally using various natural samples collected in both oceanic and coastal waters (D. Stramski and R. Reynolds, personal communication, 2012) was used to account for the decrease in the $\beta$ factor with increasing OD:

$\beta(\lambda)=3.093 \times \mathrm{OD}(\lambda)^{-0.0877}$.
This equation yields a $\beta$ factor of 4.5 for an OD of 0.014 , which was the value recommended by Röttgers and Gehnke (2012) for OD below 0.1. At this OD, however, $\beta$ equals 3.79 , resulting in $18 \%$ higher $a_{\mathrm{p}}$ for the same OD. As a result, our $a_{\mathrm{p}}$ spectra have a steeper slope toward the UV (ultraviolet) than if a constant $\beta$ would have been chosen (see Sect. 3.4). After the OD scanning, phytoplankton pigments were extracted during $18-24 \mathrm{~h}$ in methanol at room temperature (Kishino et al., 1985), which removed nearly all pigments ( $95 \%$ of sample). The filter was then placed back into the integrating sphere to measure the absorption coefficient of non-algal particles, $a_{\mathrm{NAP}}(\lambda)$. The absorption coefficient of phytoplankton, $a_{\text {phy }}(\lambda)$, was obtained by subtracting $a_{\mathrm{NAP}}(\lambda)$ from the total particulate absorption coefficient. For 14 samples out of 434 , no $a_{\mathrm{NAP}}$ data were available and the $a_{\mathrm{phy}}$ spectrum was obtained numerically following Bricaud and Stramski (1990). The spectral slopes of $a_{\text {NAP }}$ spectra, $S$ in $\mathrm{nm}^{-1}$, were calculated for three different spectral domains:

$$
\begin{aligned}
& a_{\mathrm{NAP}}(\lambda)=A \cdot e^{S^{\mathrm{UV}}\left(\lambda_{0}-\lambda\right)}+B^{\mathrm{UV}}, \\
& a_{\mathrm{NAP}}(\lambda)=A \cdot e^{S^{\mathrm{VIS}}\left(\lambda_{0}-\lambda\right)}+B^{\mathrm{VIS}}, \\
& a_{\mathrm{NAP}}(\lambda)=A \cdot e^{S^{\mathrm{UVVIS}}\left(\lambda_{0}-\lambda\right)}+B^{\mathrm{UVVIS}},
\end{aligned}
$$

where the UV, VIS and UVVIS domains corresponded to $300-500 \mathrm{~nm}$ (which extends in the blue), $400-700 \mathrm{~nm}$ and $300-800 \mathrm{~nm}$ spectral ranges, respectively. $S$ (in $\mathrm{nm}^{-1}$ ), $A$, and $B$ (in $\mathrm{m}^{-1}$ ) were calculated using a non-linear fit for the different spectral ranges using the $n l s$ function in $R$. For comparison with previous studies, we also computed $S$ for 380 $730 \mathrm{~nm}$ (excluding 400-480 and 620-710 nm ranges) following the recommendations of Babin et al. (2003).

The detailed methodology to determine the CDOM absorption coefficient is given in Matsuoka et al. (2012). Briefly, water samples were filtered using $0.2 \mu \mathrm{m}$ GHP filters (Acrodisc Inc.) to measure light absorption by CDOM using a liquid waveguide system, UltraPath (World Precision Instruments Inc.), which allowed the selection of the most appropriate optical path length in the range between 0.05 and $2 \mathrm{~m}$. In most cases, a $2 \mathrm{~m}$ optical path length was used for the measurement, except for coastal waters near the Mackenzie River mouth where a $0.1 \mathrm{~m}$ optical path length was used. The

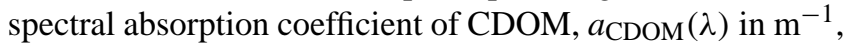
was measured from 250 to $750 \mathrm{~nm}$ with $1 \mathrm{~nm}$ increments.

\subsection{Biogeochemical measurements}

Suspended particulate matter (SPM) and particulate organic carbon (POC) concentrations were measured according to the procedure detailed in Doxaran et al. (2012). Briefly, known volumes $(V$, in $\mathrm{L})$ of seawater $(0.2-6 \mathrm{~L}$, depending on turbidity) were filtered in triplicate through pre-ashed $(5 \mathrm{~h}$ at $450^{\circ} \mathrm{C}$ ) and pre-weighed $25 \mathrm{~mm}$ glass-fiber filters (Whatman GF/F $0.7 \mu \mathrm{m}$ nominal pore size) at low vacuum (Van Der Linde, 1998). The filters were rinsed with Milli-Q water, dried for $12 \mathrm{~h}$ at $60^{\circ} \mathrm{C}$ and stored at $-80^{\circ} \mathrm{C}$ in clean Petri 
slides covered with aluminium foil. In the laboratory, filters were dried again $\left(24 \mathrm{~h}\right.$ at $\left.60^{\circ} \mathrm{C}\right)$ prior weighing, weighted and SPM was calculated dividing the difference between final weight and pre-weight by the volume filtered. POC concentration was measured on the same GF/F filters used for SPM determination using a CHN analyzer (PerkinElmer 2400, combustion at $925^{\circ} \mathrm{C}$ ).

Particulate matter for pigment analysis was collected by filtration of seawater through $25 \mathrm{~mm} \mathrm{GF} / \mathrm{F}$ filters under low vacuum. Samples were flash-frozen in liquid nitrogen after the filtration and kept at $-80^{\circ} \mathrm{C}$ until analysis. After the cruise, the filters were sent to the Laboratoire d'Océanographique de Villefranche for analysis. Pigment concentrations were determined by high-performance liquid chromatography (HPLC) following the method described by Van Heukelem and Thomas (2001), as modified by Ras et al. (2008). For this study total chlorophyll $a$ concentration ( $\left.T_{\text {chla }}\right)$ is calculated as the sum of chlorophyll $a$, divinyl chlorophyll $a$ and chlorophyllide $a$, as recommended by the National Aeronautics and Space Administration (NASA) protocol for ocean color algorithms development and validation (Hooker et al., 2005).

\subsection{Radiative transfer modeling}

The impact of non-uniform IOP vertical profiles near the sea surface (see Sect. 3.3) on light penetration and remote sensing reflectance was assessed using the Hydrolight radiative transfer model (Mobley, 1994). Hydrolight was run for different vertical distributions of particles based on our field observations.

CDOM and phytoplankton absorption coefficients were assumed vertically uniform and were kept constant for all simulations. This is justified by the fact that meltwater did not show significant differences relative to the subsurface in both CDOM and $a_{\text {phy }}$ absorption (i.e., $4 \%$, Table 2). The CDOM absorption spectra was calculated using

$a_{\mathrm{CDOM}}(\lambda)=a_{\mathrm{CDOM}}(440) e^{S_{\mathrm{CDOM}}(440-\lambda)}$

with $a_{\mathrm{CDOM}}(440)$ set to $0.03 \mathrm{~m}^{-1}$ (Table 2) and $S_{\mathrm{CDOM}}$ to $0.018 \mathrm{~nm}^{-1}$ (Matsuoka et al., 2012). The median phytoplankton absorption spectrum for water samples collected in the subsurface layer was used in all simulations (see $a_{\text {phy }}(\lambda)$ shown on Fig. A1).

Particulate IOPs were calculated using the following SPMbased relationships:

$a_{\mathrm{NAP}}(440)=0.058 \times \mathrm{SPM}^{1.13}\left(r^{2}=0.98 ;\right.$ this study, Sect. 3.6, Fig. 13)

and

$b_{\mathrm{p}}(555)=0.88 \times \operatorname{SPM}\left(r^{2}=0.98 ;\right.$ Doxaran et al., 2012),

where, $b_{\mathrm{p}}$ is the total particles scattering coefficient and SPM is expressed in $\mathrm{mg} \mathrm{L}^{-1}$. The spectral shape of $b_{\mathrm{p}}$ was obtained using a power function with a spectral dependency of $\lambda^{-0.5}$, an averaged value measured offshore during MALINA (Doxaran, unpublished). The spectral $a_{\text {NAP }}$ coefficient was calculated using Eq. (3) with $S_{\mathrm{NAP}}$ set to $0.094 \mathrm{~nm}^{-1}$ (Sect. 3.4) and the offset $\left(B_{\mathrm{NAP}}\right)$ as

$B_{\mathrm{NAP}}=0.004 \times \operatorname{SPM}^{1.25}\left(r^{2}=0.96 ;\right.$ this study $)$.

The particle phase function was calculated using the Fournier and Forand model (Mobley et al., 2002) with a ratio of particles backscattering coefficient $\left(b_{\mathrm{bp}}\right)$ to particles scattering coefficient, $b_{\mathrm{bp}}: b_{\mathrm{p}}$, of $1.5 \%$ (Doxaran et al., 2012), which was assumed as vertically homogenous. Raman scattering, CDOM and chlorophyll fluorescence were included in all model runs. The simulations were performed for clear sky conditions resembling those at a latitude of $71^{\circ} \mathrm{N}$ at noontime on 1 August and with a seawater surface roughened by a wind speed of $4 \mathrm{~m} \mathrm{~s}^{-1}$. Computations were made at every $10 \mathrm{~nm}$ from 300 to $700 \mathrm{~nm}$. The vertical variation of the input IOPs were controlled by the vertical variation of SPM, which was modeled using three different approaches: (i) fully mixed column, (ii) two homogenous layers, and (iii) SPM linearly decreasing with depth. These SPM profiles resulted in 7 different IOP profiles that were input into Hydrolight, yielding 7 runs (Table 1). The chosen SPM concentrations were based on observations presented in Table 2 (Sect. 3.3): (i) $0.11 \mathrm{mg} \mathrm{L}^{-1}$ was the median concentration observed in the subsurface waters, (ii) $0.4 \mathrm{mg} \mathrm{L}^{-1}$ corresponded to a 3.6-fold particle enrichment near the surface, and (iii) $1.1 \mathrm{mgL}^{-1}$ corresponded to a 10 -fold particle enrichment near the surface.

\section{Results and discussion}

\subsection{Sea ice and wind conditions and water masses definition}

Nearly $2 / 3$ of the sampling area was affected by melting sea ice during the MALINA survey (Fig. 1). The total ice concentration increased from $3 / 10$ to $9 / 10$ from the inner shelf to offshore. Old ice in vast floes $(2-10 \mathrm{~km})$ occupied the major fraction of it $(2 / 10$ to $8 / 10)$, while large floes $(0.5-2 \mathrm{~km})$ of thick $(>120 \mathrm{~cm})$ first-year ice were also encountered in lower concentration $(<2 / 10)$.

These slightly above-normal sea ice concentrations compared to previous years were the result of relatively strong and sustained northly/northeasterly wind conditions prevailing in July (Forest et al., 2013). In August, calm to moderate southerly wind conditions dominated, transporting the ice pack northward (Forest et al., 2013).

Sea ice meltwater has an important impact on the nearsurface salinity. To support the interpretation of the data, the water masses definition proposed by Matsuoka et al. (2012) was adopted and slightly modified to account for the sources of freshwater in the surface layer. Using the salinity vs. $a_{\mathrm{CDOM}}(350)$ relationship (Fig. 2), two freshwater endmembers, namely the ice meltwater (red) and the river-influenced 
Table 1. Modeling of the vertical structure of the water column for RTF simulations.

\begin{tabular}{lrr}
\hline Run \# & Vertical structure & $\mathrm{SPM}\left(\mathrm{g} \mathrm{m}^{-3}\right)$ \\
\hline 1 & one homogeneous layer & 0.11 \\
2 & one homogeneous layer & 0.4 \\
3 & one homogeneous layer & 1.1 \\
4 & two homogeneous layers & $0.4(0-$ to $1 \mathrm{~m}), 0.11(>1 \mathrm{~m})$ \\
5 & two homogeneous layers & $1.1(0-$ to $1 \mathrm{~m}), 0.11(>1 \mathrm{~m})$ \\
6 & linearly decreasing & $0.4-0.1(0-$ to $2 \mathrm{~m}), 0.11(>2 \mathrm{~m})$ \\
7 & linearly decreasing & $1.1-0.1(0-$ to $2 \mathrm{~m}), 0.11(>2 \mathrm{~m})$ \\
\hline
\end{tabular}

Table 2. Comparison between samples collected just below the sea surface (0-) and that at approximately 2-3 m depth (subsurface from the rosette) of absorption coefficients. Median values are presented with minimum and maximum in parenthesis.

\begin{tabular}{lrrrr}
\hline Parameter (unit) & $N$ & $0-$ & subsurface & $0-$ : subsurface \\
\hline$a_{\mathrm{p}}(440)\left(\mathrm{m}^{-1}\right)$ & 22 & $0.023(0.013 ; 0.186)$ & $0.011(0.004 ; 0.24)$ & $1.8(0.8 ; 4.4)$ \\
$a_{\mathrm{NAP}}(440)\left(\mathrm{m}^{-1}\right)$ & 22 & $0.018(0.008 ; 0.114)$ & $0.004(0.002 ; 0.13)$ & $3.2(0.9 ; 10.8)$ \\
$a_{\text {phy }}(440)\left(\mathrm{m}^{-1}\right)$ & 22 & $0.007(0.003 ; 0.072)$ & $0.006(0.003 ; 0.115)$ & $0.97(0.56 ; 4.02)$ \\
$a_{\mathrm{CDOM}}(440)\left(\mathrm{m}^{-1}\right)$ & 19 & $0.032(0.02 ; 0.18)$ & $0.028(0.019 ; 0.15)$ & $1.04(0.9 ; 1.3)$ \\
POC $\left(\mathrm{mgL}^{-1}\right)$ & 14 & $0.058(0.034 ; 0.38)$ & $0.26(0.003 ; 0.13)$ & $2.3(1.13 ; 19.7)$ \\
SPM $\left(\mathrm{mgL}^{-1}\right)$ & 14 & $0.29(0.14 ; 3.41)$ & $0.11(0.04,0.94)$ & $3.6(1.18 ; 24.6)$ \\
POC $: \mathrm{SPM}(\%)$ & 14 & $21.9(1.6 ; 38.7)$ & $23.7(6.5 ; 34)$ & $1.12(0.05 ; 3.7)$ \\
$a_{\mathrm{NAP}}^{*}(440)\left(\mathrm{m}^{2} \mathrm{~g}^{-1}\right)$ & 14 & $0.065(0.004 ; 0.11)$ & $0.045(0.014 ; 0.13)$ & $1.21(0.1 ; 5.7)$ \\
\hline
\end{tabular}

waters (black), were identified. A third water mass falling in between the two mixing lines of river and ice meltwater, respectively, was identified as a mixture between the two freshwater endmembers and the seawater (green). Based on salinity, five water masses were identified: the Upper Polar Mixed Layer (UPML; $24<S<28$; blue), Lower Polar Mixed Layer (LPML; $28<S<30.7$; cyan), Pacific Summer Water (PSW; $30.7<S<32.3$; magenta), Pacific Winter Water or Upper Halocline (PWW/UH; $32.3<S<33.9$; yellow), and Lower Halocline Water (LHW; $33.9<S<35$; grey)(Matsuoka et al., 2012, and ref. therein).

The majority (90\%) of the water samples collected within the depth of $3 \mathrm{~m}$ were characterized by low salinity $(<28)$ and classified as UPML water. The LPML, which typically occupies the first $50 \mathrm{~m}$, only extended to the surface (instead of the UPML) at a few stations located near Cape Bathurst and Banks Island at the entrance of the Amundsen Gulf (stations 110, 135, 170 and 260). Below the LPML, the PSW extended to $\sim 100 \mathrm{~m}$ and overlaid the UH or PWW. The LHW was sampled only 5 times at depths exceeding $200 \mathrm{~m}$. The water masses distribution plays an important role in explaining the distribution of optical components as shown by Matsuoka et al. (2012) for CDOM.

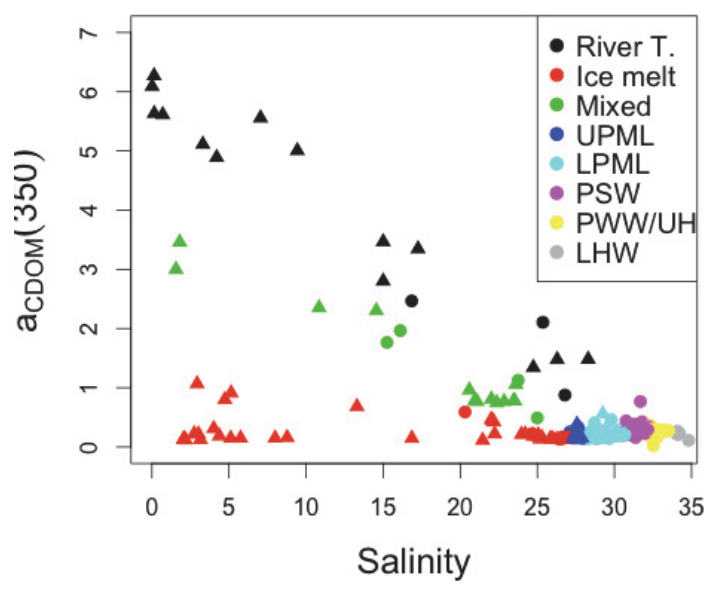

Fig. 2. $a_{\mathrm{CDOM}}(350)$ versus salinity. Color-coded symbols are used to identify the water masses following Matsuoka et al. (2012) (see text for acronyms). Triangles denote surface samples collected at a depth $<3 \mathrm{~m}$.

\subsection{Spatial variability of absorbing components}

\subsubsection{Horizontal variability}

The shelf-wide, near-surface horizontal variability, as measured from the barge vessel, of each absorbing component is shown in Fig. 3. The blue wavelength $(440 \mathrm{~nm})$ is chosen because at this wavelength all three optically active components absorb light significantly. Phytoplankton absorption 

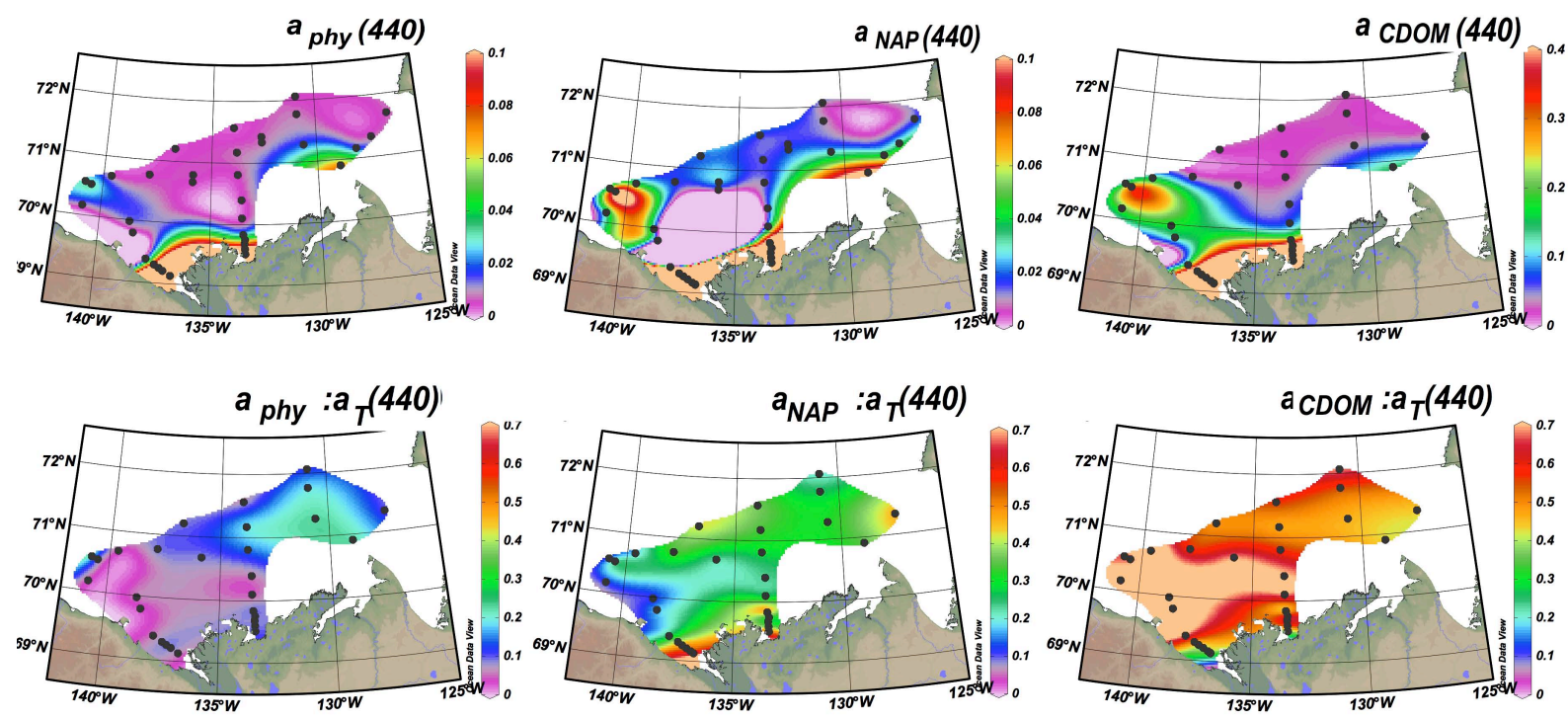

Fig. 3. Horizontal variability of absorption coefficients at $440 \mathrm{~nm}$ in the surface waters for phytoplankton (left), NAP (center) and CDOM (right), and their contribution to the total non-water absorption (bottom panels).

was generally low in the surface layer except near the river delta, west of the Mackenzie Canyon (station 760; Fig. 1) and at the station nearest to Cap Bathurst at the eastern end of the Mackenzie shelf (station 170; Fig. 1). The highest contribution of $a_{\text {phy }}$ to the total non-water absorption, $a_{\mathrm{T}}$ (i.e., $\left.a_{\mathrm{phy}}+a_{\mathrm{CDOM}}+a_{\mathrm{NAP}}\right)$ is $\sim 25 \%$ in the eastern part of the sampling area. This sector is known for its relatively high primary productivity due to frequent coastal upwelling of nutrient-rich Pacific water (Williams and Carmack, 2008; Tremblay et al., 2011).

The non-algal particles component had a spatial distribution somehow similar to that of $a_{\text {phy }}$, but its contribution to $a_{\mathrm{T}}$ was quite different. First, $a_{\mathrm{NAP}}$ dominated the light absorption in the river delta $(>70 \%)$. Outside the river delta, $a_{\mathrm{NAP}}: a_{\mathrm{T}}$ varied between 20 and $40 \%$, except in the western side of the shelf where the Mackenzie River plume was flowing (i.e., $<20 \%$ ). This was evidenced by the distribution of CDOM (Figs. 3, 4), which was dominating the blue light absorption (50\%) nearly everywhere, except in the high turbidity zone of the Mackenzie River delta where non-algal particles absorption dominated.

\subsubsection{Vertical variability}

Three cross sections from the inner shelf to offshore are presented in Figs. 4-6. The western section (Fig. 4) shows the strong impact of the Mackenzie River plume on the surface optical properties with low $a_{\text {phy }}$, moderate $a_{\mathrm{NAP}}$ and high $a_{\mathrm{CDOM}}$ within the first $10 \mathrm{~m}$ of the water column. $a_{\mathrm{CDOM}}$ and $a_{\mathrm{NAP}}$ values at the surface were $\sim 0.15$ and $\sim 0.05 \mathrm{~m}^{-1}$, respectively. Light profiles measured with the C-OPS indicated that the top $10 \mathrm{~m}$ layer absorbed between 70 and $88 \%$ of the incident radiation at $443 \mathrm{~nm}$, decreasing the amount of photosynthetically usable radiation (PUR) for phytoplankton underneath the river plume. There, both NAP and phytoplankton absorption coefficients were low $\left(0.03 \mathrm{~m}^{-1}\right)$ and contributed little to $a_{\mathrm{T}}$, while CDOM largely dominated the blue light absorption ( $80 \%$ ). A patch of higher $a_{\text {phy }}$ and $a_{\text {NAP }}$ at $\sim 80 \mathrm{~m}$ and $70^{\circ} \mathrm{N}$ was well below the $1 \%$ blue light level ( $\sim 50 \mathrm{~m}$, not shown). This feature could be resulting from the shelf to basin advection of particles, which is known to occur in the Kugmallit Canyon located nearby (Forest et al., 2007; O'Brien et al., 2006).

The cross section in the middle shelf (Fig. 5) begins at the Kugmallit Bay mount, follows along the Kugmallit Canyon and extends beyond the shelf break. Based on the CDOM distribution, the source of the low salinity surface water could be identified as either originating from the river discharge (southern portion of section) or from sea ice meltwater (northern portion of section). All three absorption components were found in high concentration in the riverinfluenced water. Although $a_{\text {phy }}$ and $a_{\text {NAP }}$ had a similar vertical distribution with higher concentration inshore and near the bottom of the shelf, their respective contribution to $a_{\mathrm{T}}$ differed markedly. $a_{\text {NAP }}$ was the dominant absorbing component south of $70^{\circ} 20^{\prime} \mathrm{N}$ and along the shelf bottom. Offshore where the multiyear ice coverage was $\geq 5 / 10$ (Fig. 1), the contribution of $a_{\mathrm{NAP}}$ to $a_{\mathrm{T}}$ near the surface reached $34 \%$ measured at station 340 from the barge. The $a_{\text {phy }}$ contribution to blue light absorption was generally low $(<10 \%)$, except between the depth of 40 to $60 \mathrm{~m}$ where it reached $23 \%$ in the subsurface chlorophyll maximum (SCM). The SCM was just beneath the $10 \%$ light level at $443 \mathrm{~nm}$ suggesting that PUR was sufficient at this depth for phytoplankton photosynthesis even with intermittent ice coverage. Nevertheless, $a_{\mathrm{CDOM}}$ 


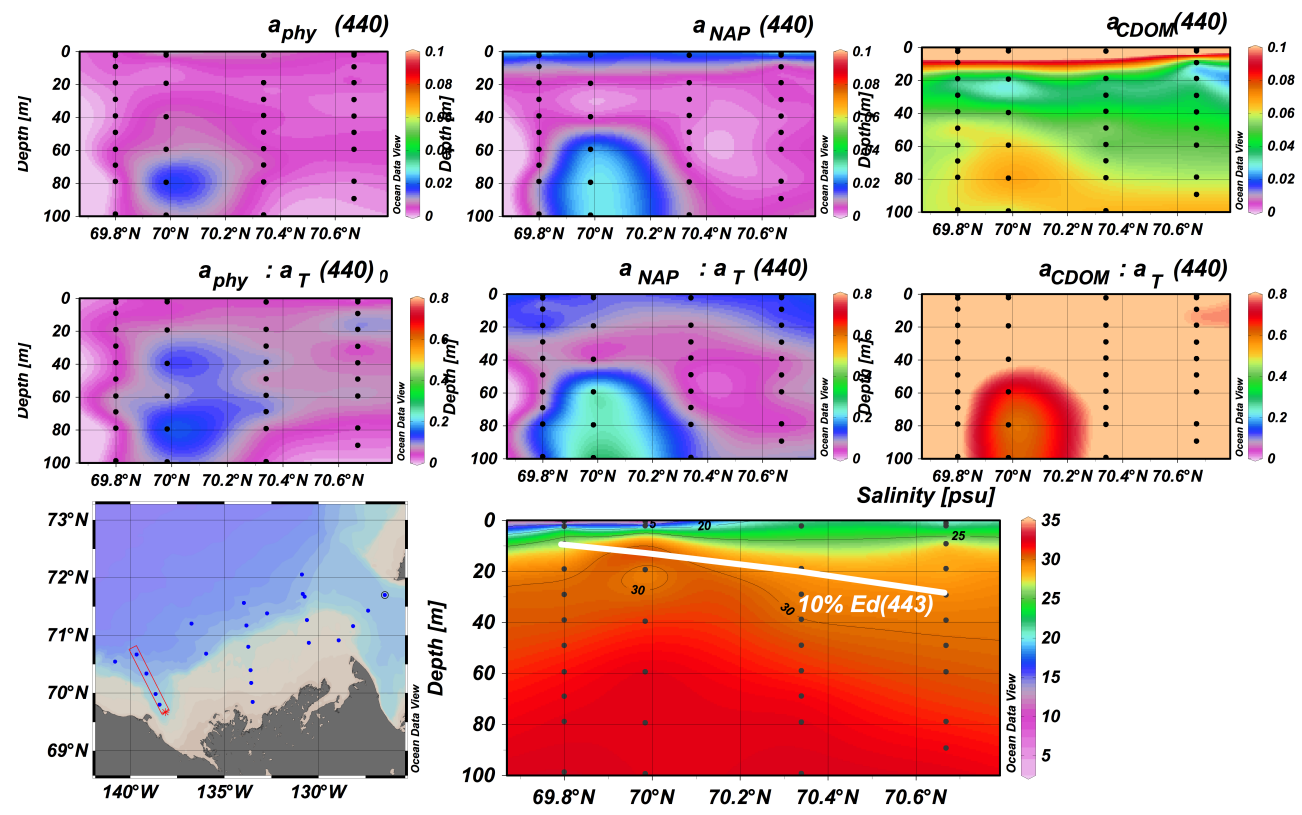

Fig. 4. Vertical variability of phytoplankton (left), non-algal particles (center) and colored dissolved organic matter (right) absorption coefficients at $440 \mathrm{~nm}$ along a cross section over the Mackenzie Canyon, and their contribution to total non-water absorption (middle panels). Salinity distribution is shown in the bottom panel together with the $10 \%$ light level penetration at $443 \mathrm{~nm}$. Stations were visited between 10 and 12 August 2009.
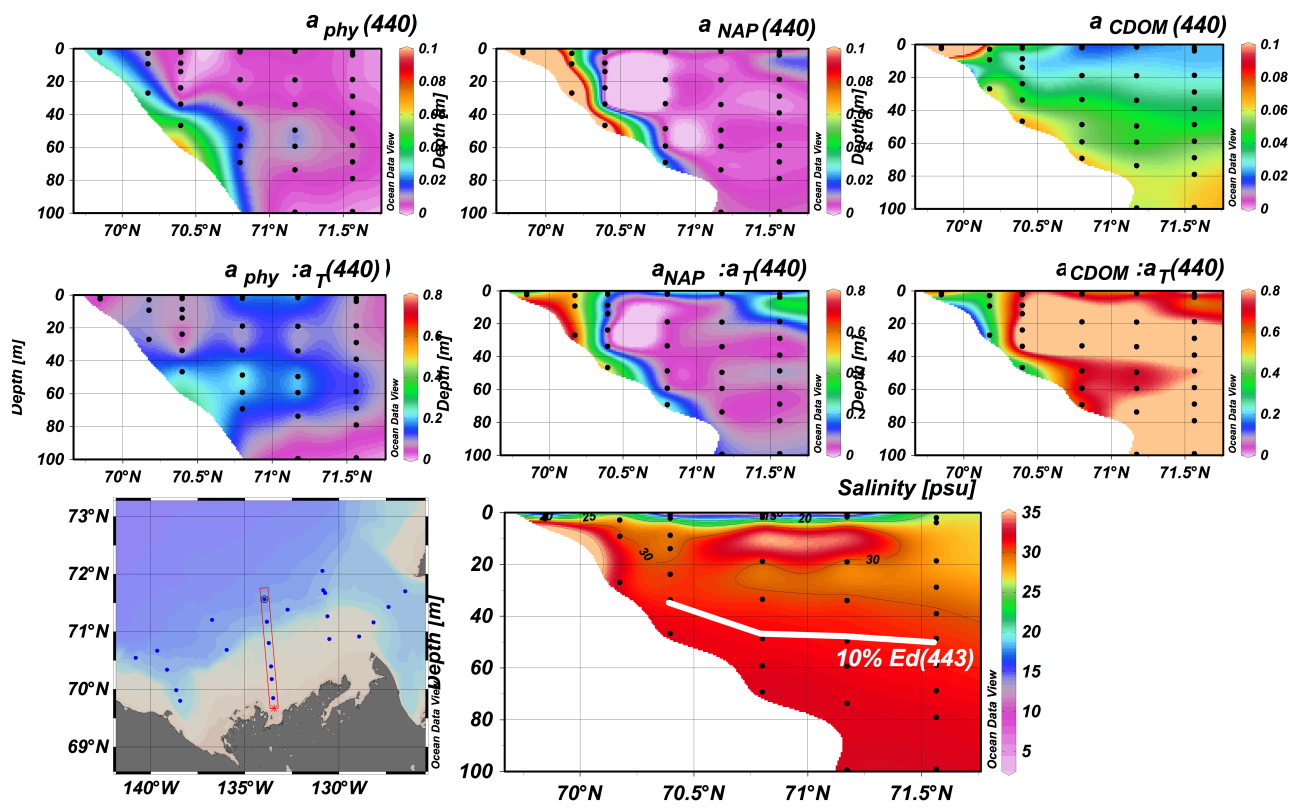

Fig. 5. Same as Fig. 4, but for the middle shelf transect visited between 31 July and 9 August.

played the dominant role in the light absorption budget, contributing to more than $50 \%$ of the blue light absorption, even in the SCM $(70 \%)$.

The most eastern section crossed the entrance to the Amundsen Gulf from in the near of Cap Bathurst (station 170) to in the near of Banks Island (station 110) (Fig. 6). At station 170, the 10 and $1 \%$ light levels in the blue $(443 \mathrm{~nm})$ were found at only 4.8 and $17 \mathrm{~m}$, respectively, where phytoplankton absorption was maximum $\left(0.12 \mathrm{~m}^{-1}\right)$. The high biological productivity at this location is explained by the upwelling of nutrient-rich waters near Cap Bathurst (Williams and Carmack, 2008; Tremblay et al., 2011). The SCM, where $a_{\text {phy }}$ contributed to $\sim 40 \%$ of $a_{\mathrm{T}}$, developed at $40 \mathrm{~m}$ depth near the shelf break and deepened to $60 \mathrm{~m}$ when going 

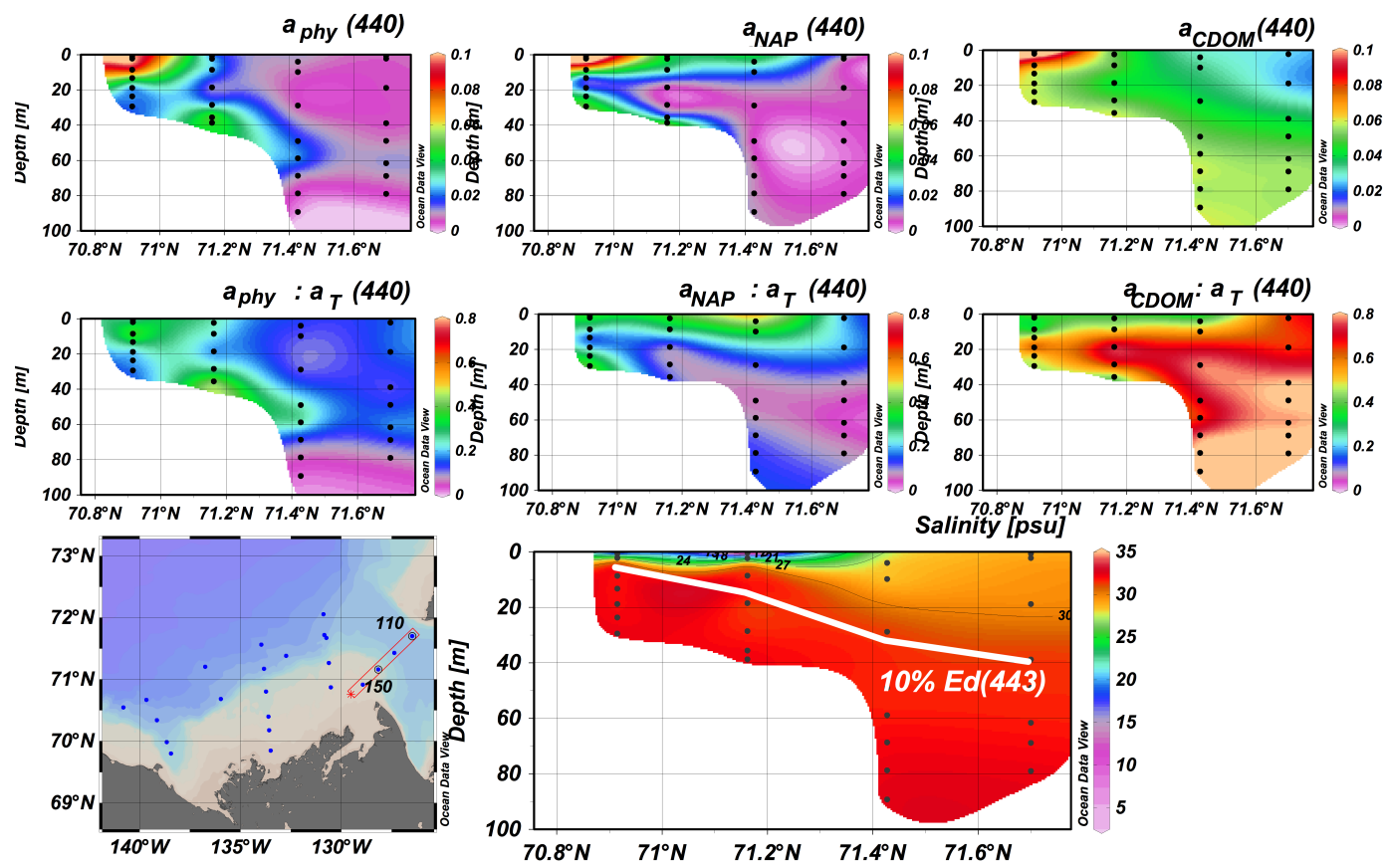

Fig. 6. Same as Fig. 4, but for the section located at the entrance of the Amundsen Gulf visited between 6 and 7 August.

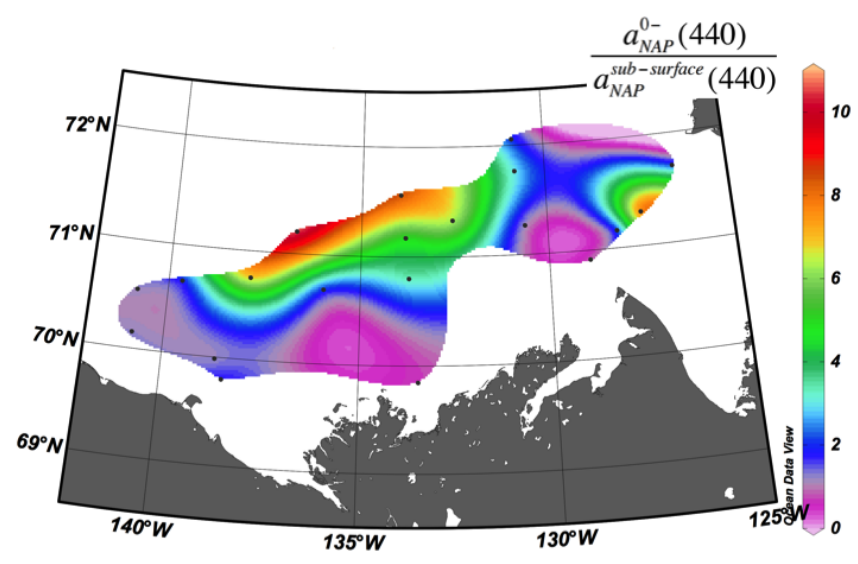

Fig. 7. Map showing the non-algal particle enrichment near the sea surface. The ratio between $a_{\mathrm{NAP}}(440)$ just below the sea surface $\left(a_{\mathrm{NAP}}^{0-}\right)$ and that at $\sim 2-3 \mathrm{~m}$ depth $\left(a_{\mathrm{NAP}}^{\text {subsurface }}\right)$ is shown in color scale.

northeastward towards the middle of the section. A relatively important contribution of $a_{\mathrm{NAP}}$ to $a_{\mathrm{T}}$ at the surface was found in the middle of the channel $(\sim 46 \%)$. CDOM absorption was high in surface waters near Cap Bathurst $\left(0.13 \mathrm{~m}^{-1}\right)$, where also phytoplankton pigment concentrations were higher, and decreased northeastward. Its relative importance to $a_{\mathrm{T}}$, however, showed the opposite trends with increasing contributions northeastward from about $35-65 \%$.

\subsection{Particles enrichment near the sea surface}

The non-homogenous vertical distributions of the three absorbing components in the euphotic zone warrant more attention. Thanks to the MALINA sampling strategy adopted for the optical measurements, it was possible to collect near surface samples in an undisturbed water column. This is usually difficult to achieve onboard a large icebreaker. In this section we present evidence of an enrichment in particles near the sea surface. This was almost systematically observed during MALINA when comparing near surface samples collected from the barge or zodiac (hereinafter denoted as $0-$ ) and from the rosette Niskin bottle closest to the surface (hereinafter referred to as subsurface).

\subsubsection{Impacts on particulate absorption}

The spatial distribution of $a_{\mathrm{NAP}}^{0-}: a_{\mathrm{NAP}}^{\text {subsurface }}$ showed an increase in NAP from the shelf to the deep basin (Fig. 7). This increase was spatially coherent with the multiyear ice distribution and concentration (Fig. 1) suggesting that particles likely originated from sea ice melting and not from the river discharge.

Comparisons between subsurface and near-surface total particle absorption, SPM and POC also show a similar pattern as $a_{\mathrm{NAP}}$, but not for phytoplankton pigment and CDOM absorption coefficients (Table 2). The near-surface particles originate most likely predominantly from organic matter as suggested by the high contribution of POC to SPM of $20 \%$ (Table 2; Doxaran et al., 2012). Assuming that POM = $2.6 \times$ POC (Copin-Montgut, 1980), which is valid for freshly 

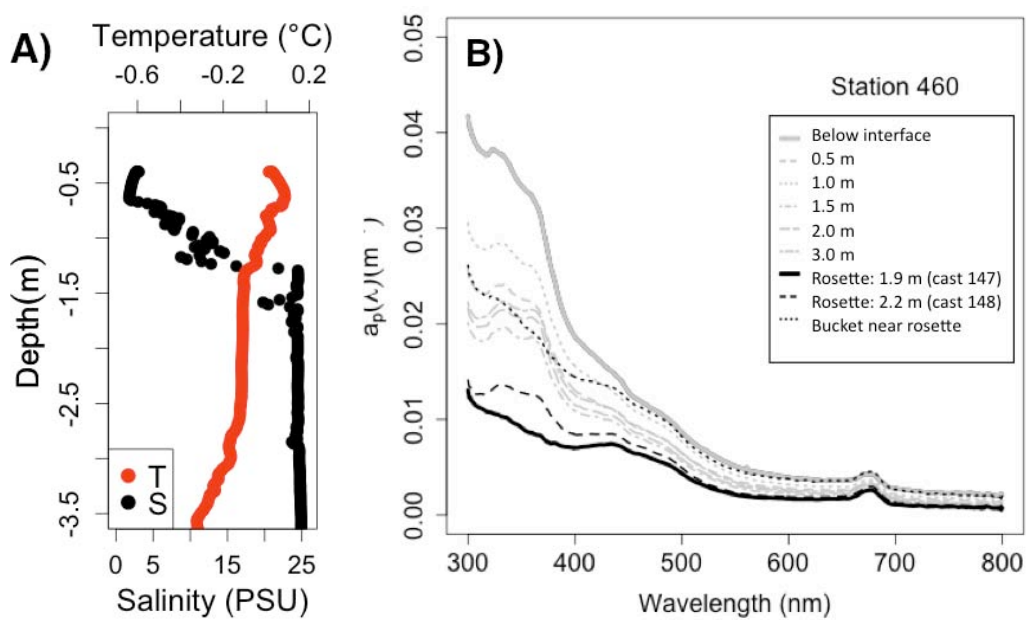

Fig. 8. (A) near-surface variability of salinity and temperature measured from the CTD attached to an optical package deployed from the barge at station 460 on 19 August. (B) spectral absorption of particles sampled manually near the sea surface from the barge using a Kemmerer bottle (grey curves) and from two rosette casts (147 and 148). An additional bucket sample was collected from the ship deck simultaneous with the rosette cast \#148 less than $3 \mathrm{~m}$ apart.

Table 3. Impact of particle enrichment near the sea surface on PAR and PUR transmission, averaged diffuse attenuation coefficient, remote sensing reflectance and band ratio-based empirical $T_{\text {chla }}$ retrievals

\begin{tabular}{lrrrrrr}
\hline Run \# & $\% \operatorname{PAR}(z=2)$ & $\% \operatorname{PUR}(z=2)$ & $K_{\mathrm{d}}^{0-5 \mathrm{~m}}(440)$ & $K_{\mathrm{d}}^{0-10 \mathrm{~m}}(440)$ & $R_{\mathrm{rs}}(440)$ & Modeled $T_{\text {chla }}$ \\
\hline 1 & 66.5 & 76.1 & 0.074 & 0.074 & 0.00255 & 0.240 \\
2 & 63.1 & 71.2 & 0.109 & 0.109 & 0.00176 & 0.310 \\
3 & 54.4 & 59.5 & 0.205 & 0.205 & 0.00097 & 0.431 \\
4 & 65.0 & 73.9 & 0.081 & 0.078 & 0.00241 & 0.248 \\
5 & 60.7 & 68.1 & 0.098 & 0.087 & 0.00208 & 0.269 \\
6 & 64.9 & 73.8 & 0.082 & 0.078 & 0.00241 & 0.249 \\
7 & 60.6 & 68.0 & 0.103 & 0.089 & 0.00208 & 0.271 \\
\hline
\end{tabular}

produced organic matter, POM would contribute to a maximum of $\sim 60 \%$ of SPM. The mass-specific absorption of NAP $\left(a_{\mathrm{NAP}}^{*}\right)$ was on average $21 \%$ higher for near-surface particles $\left(0.065 \mathrm{~m}^{2} \mathrm{~g}^{-1}\right)$ compared to the subsurface particles $\left(0.045 \mathrm{~m}^{2} \mathrm{~g}^{-1}\right)$. For comparison, the former $a_{\mathrm{NAP}}^{*}$ average value was close to the upper range observed in the Baltic Sea where organic particles dominate (Babin et al., 2003, and references therein), while the latter was around the average reported by Babin et al. (2003) for European coastal waters. The relatively high $a_{\mathrm{NAP}}^{*}$ also indicates that the near-surface particles were organically rich and were more colored than the ones found in the subsurface.

The particle enrichment in the near-surface layer was likely associated with the horizontal spreading of meltwater from multiyear ice during almost wind-free conditions (Forest et al., 2013, their Fig. 2). CTD measurements from the barge showed a thin layer of freshwater resulting from melting conditions at the most offshore stations. This layer was characterized by low CDOM, and low chlorophyll $a$ $\left(<0.1 \mathrm{mg} \mathrm{m}^{-3}\right)$, but relatively higher NAP concentration. Note that the CDOM absorption did not differ markedly between the near surface layer and the water below (Table 2), but generally tended to be slightly higher near the surface. To illustrate this vertical feature, temperature and salinity profiles within the top $3.5 \mathrm{~m}$ of the water column of station 460 are shown in Fig. 8a. This station was located within the marginal ice zone characterized by a total sea ice concentration of $3 / 10$ mostly made of large floes of old ice (Fig. 1). Station 460 was located where we examined in most detail the vertical variability in the absorbing components and adressed the impact of the sampling strategy adopted for the barge operation (see Sect. 2.1). The profile started at $0.45 \mathrm{~m}$ below the sea surface, which was about as close to the surface we could get with the CTD attached to the IOP package. Note that the $0.45 \mathrm{~m}$ depth observations were recorded after a $5 \mathrm{~min}$ instrument warm-up time a $2 \mathrm{~m}$ depth preceding the vertical cast. The salinity at $0.45 \mathrm{~m}$ was around 3 and remained constant down to $0.6 \mathrm{~m}$ from where a sharp halocline led to a salinity increase to about 25 at $1.4 \mathrm{~m}$ depth (Fig. 8a). Nine water samples were collected in the top $2.2 \mathrm{~m}$ using sampling vessels including a clean bucket deployed simultaneously with the rosette from the icebreaker, 
and a handheld Kemmerer water sampling bottle closed at five different depths from the barge (see Sect. 2.1).

The total particulate absorption spectra for each of the nine samples collected at station 460 showed significant absorption in the NIR (near infrared) portion of the spectrum (Fig. 8b). This could be attributed to absorption by NAP, which dominated the overall particulate absorption. Phytoplankton absorption peaks in the red $(676 \mathrm{~nm})$, blue $(430$ $490 \mathrm{~nm})$ and UV (310-380 nm) indicated the presence of phytoplankton pigments but, unlike NAP, these did not show significant variation with depth. A vertical gradient in $a_{\mathrm{p}}$ was present with the highest values obtained for the sample collected with the Kemmerer sampling bottle placed horizontally just below the sea surface to avoid the surface micro layer (solid grey curve) and the lowest for the rosette Niskin bottle samples (solid black curve in Fig. 8b). The higher $a_{\mathrm{p}}$ values for the bucket sample taken nearby the rosette cast (\#148) confirmed that the vertical gradient was a feature present in waters near the icebreaker as well. These results suggest that the particle enrichment was not an artifact from the sampling strategy and reinforce the hypothesis that these particles originated from the melting sea ice (the source of fresh water). This feature was usually not observed using a standard rosette Niskin bottle sampling strategy that integrated waters from a vertical range of about $1-2 \mathrm{~m}$ at a depth usually a few meters beneath the surface for the shallowest sample.

The question that remains is to what proportions the particles released by the sea ice, which were organically rich and highly absorbing, were from (1) atmospheric origin that had accumulated in multiyear ice over time, (2) clay or silt particles entrained into the ice from the water column during the ice formation and/or scouring, or (3) from autochthonous origin produced in situ by sea ice microorganisms. This question cannot be addressed specifically using our data set. Here we rather propose a few hypotheses.

First, light-absorbing impurities in Arctic snow, including black carbon $(\mathrm{BC})$ resulting from the incomplete combustion and dust, have been the subject of several recent studies due to their effect on the radiative forcing (Flanner et al., 2011; Goldenson et al., 2012). Doherty et al. (2010), who analyzed 1200 snow or ice samples across the Arctic, reported an average $\mathrm{BC}$ concentration in the Arctic Ocean of $8 \mathrm{ng}$ of $\mathrm{BC}$ per $\mathrm{g}$ of snow or ice, with values reaching up to $23 \mathrm{ng} \mathrm{g}^{-1}$ in melting sea ice. Assuming a sea ice density of $910 \mathrm{~kg} \mathrm{~m}^{-3}$ and a $\mathrm{BC}$ concentration of $23 \mathrm{ng} \mathrm{g}^{-1}$ would yield a concentration of $0.021 \mathrm{~g} \mathrm{BC} \mathrm{m}^{-3}$ (or $\mathrm{mgL}^{-1}$ ) in pure meltwater. For comparison, we measured an average concentration of POC just below the sea surface of $0.058 \mathrm{mg} \mathrm{L}^{-1}$ with a maximum value of $0.38 \mathrm{mgL}^{-1}$ (Table 2). BC particles are, however, known to have a very high mass-specific absorption coefficient (also known as mass-normalized absorption cross section) at $550 \mathrm{~nm}$ of $7.5 \pm 1.5 \mathrm{~m}^{2} \mathrm{~g}^{-1}$ (Bond and Bergstrom, 2005). This value is an order of magnitude larger than our measured $a_{\mathrm{NAP}}(443)$ normalized by POC $\left(0.31 \mathrm{~m}^{2} \mathrm{~g}^{-1}\right.$ of
POC). It is not clear, however, what fraction of POC can be considered as $\mathrm{BC}$, but the above result suggests that $\mathrm{BC}$ could only have comprised a minor fraction of the total particles, yet still having a significant potential effect on near-surface absorption characteristics.

Second, it was recently found that Arctic DOM in the surface waters, originating from ice algae and/or phytoplankton, is prone to assemble spontaneously to form organic gels that range in size from colloidal to micrometer sizes (Orellana et al., 2011). Orellana et al. (2011) reported faster gel formation in both surface micro layer (SML) and subsurface Arctic waters and with higher microgel yields than at lower latitudes. This was likely due to the high abundance of polymer gels produced by marine microbes and the presence of hydrophobic moieties. The latter were found to be relatively abundant in the SML (see Orellana et al., 2011, for details). The particle enrichment observed in our study was, however, spatially associated with multiyear ice. Sea ice algae are known to produce exopolymeric substances (EPS) that contribute significantly to the first-year ice POC pool, as well as DOM (see Thomas et al., 2010, and ref. therein).

\subsubsection{Impacts on light transmission and remote sensing reflectance}

In this section we further examine the impacts of the near surface particle enrichment on the spectral light transmission and remote sensing reflectance $\left(R_{\mathrm{rs}}\right)$. Seven Hydrolight radiative transfer model runs were performed considering a fully homogenous water column (\#1 to \#3), a two-layer system characterized by a thin layer of freshwater $(1 \mathrm{~m})$ enriched in SPM (\#4 and \#5), and a linearly decreasing concentration of SPM from $0-$ to $2 \mathrm{~m}$ overlaying a vertically homogenous water column (\#6 and \#7) (see Sect. 2.4 and Appendix Figs. A2-A4).

Figure 9a presents the spectral scalar irradiance $\left(E^{0}(\lambda)\right.$ in $\mu$ mol photon $\mathrm{m}^{-2} \mathrm{~s}^{-1}$ ) reaching $2 \mathrm{~m}$ for each run. We calculated the fraction of the incident photosynthetically available or usable radiation (PAR and PUR) transmitted across the top $2 \mathrm{~m}$ of the water (Table 3 ). PUR was calculated as proposed by Morel (1978):

$$
\text { PUR }=\int_{\lambda=400}^{700} E^{0}(\lambda) \cdot \frac{a_{\text {phy }}(\lambda)}{a_{\text {phy }}(443)} \mathrm{d} \lambda .
$$

Under low particle concentration and vertically homogenous water column (run \#1), 66.5 and $76.1 \%$ of PAR and PUR, respectively, would be transmitted through the first $2 \mathrm{~m}$ of the water column (Table 2). A 10-fold increase in NAP in the surface waters would further reduce PAR and PUR transmission by $\sim 6$ and $\sim 8 \%$ respectively. The median case, i.e., a 3.6fold enrichment, was found to have little impact on the light transmission $(<3 \%)$. Considering that particles mostly absorb UV and visible radiation and that about $50 \%$ of the solar 

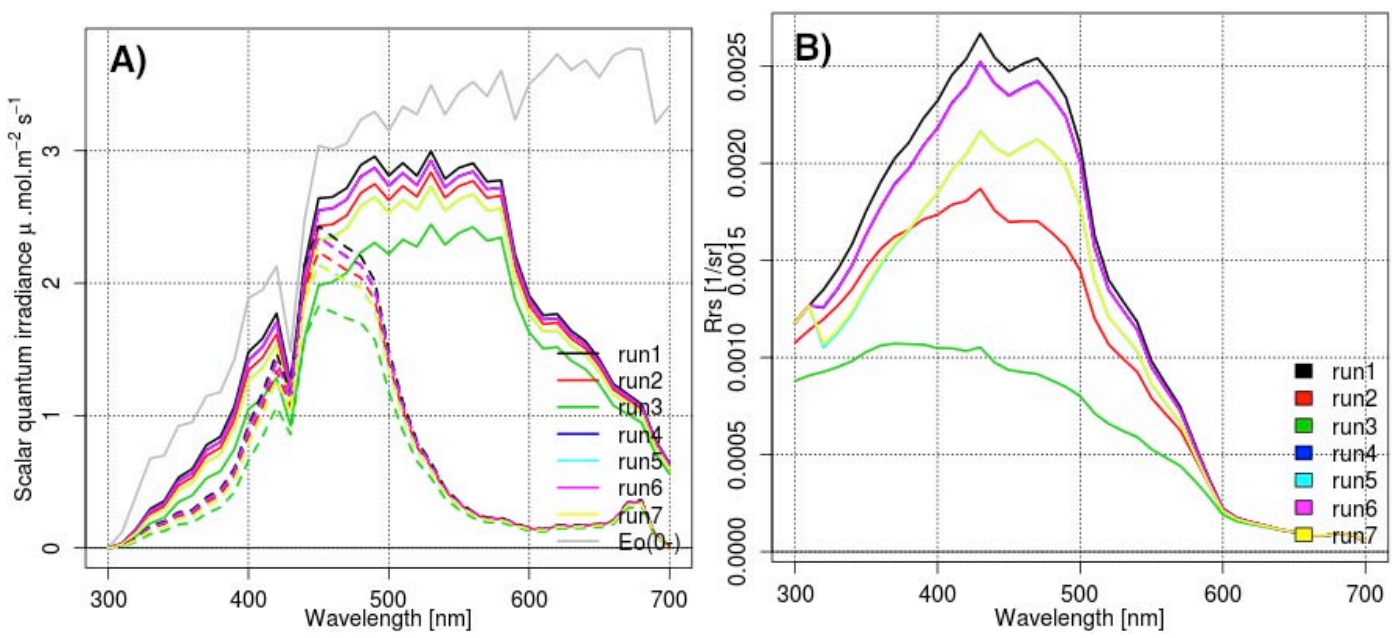

Fig. 9. Hydrolight simulation results: (A) spectral scalar irradiance (solid lines) and spectral scalar irradiance normalized by $a_{\text {phy }}(\lambda)$ : $a_{\text {phy }}(440)$ (dashed lines) at $2 \mathrm{~m}$ depth; (B) remote sensing reflectance. Note that $R_{\mathrm{rs}}$ for runs 4 and 6 are practically equal. Idem for runs 5 and 7.

energy is in the near infrared, the impact of the particle enrichment on the ocean heating rate was probably negligible.

The impact of the particle enrichment on $K_{\mathrm{d}}$ depends on the thickness of the layer considered for its calculation. For example, if $K_{\mathrm{d}}(440)$ is calculated from the surface to $10 \mathrm{~m}$, its value would increase by only $\sim 5 \%$ for a 3.6 -fold enrichment and $\sim 20 \%$ for a 10 -fold enrichment (Table 2). If $K_{\mathrm{d}}(440)$ is averaged for the top $5 \mathrm{~m}$, then the values are increased by $\sim 10$ and $\sim 30 \%$ for the two situations, respectively. These results indicate that large errors can be made if one uses an averaged surface $K_{\mathrm{d}}$ to propagate light throughout the water column.

The remote sensing reflectance was decreased by the particle enrichment at wavelengths shorter than $600 \mathrm{~nm}$. This due to the low values of $b_{\mathrm{b}}: a$ of NAP in the blue-green part of the spectrum. Surprisingly, $R_{\mathrm{rs}}$ at longer wavelengths $(>600 \mathrm{~nm}$ ) did not increase significantly by the presence of particles. This was because NAP absorbed efficiently in the red part of the spectrum (cf. Figs. 8b, A3) thus compensating for the increase in light backscattering due to particles. Indeed, the particles such as those released from melting sea ice are essentially made up of organic matter $(\sim 60 \%$ of POM, see above), with moderate backscattering efficiency ( $b_{\mathrm{bp}}: b_{\mathrm{p}} \sim 1.5 \%$; Doxaran et al., 2012) and with a relatively high mass-specific absorption coefficient (Table 2).

Runs \#2 and \#3 illustrate the magnitude of the error caused by an assumption of a fully homogenous water column containing the SPM measured near the sea surface using a bucket. For the 10-fold enrichment case, for example, the $R_{\mathrm{rs}}$ signal modeled using homogenous conditions (\#3) was $\sim 50 \%$ lower than for a more realistic case (\#5 and \#7). $R_{\mathrm{rs}}$ estimation for run \#4 closely matched the one obtained from \#6. This ressemblance was also revealed with runs \#5 and \#7. The foregoing results emmerge from the similitude in the integrated IOPs of the water column despite its optically distinct structure. This indicates that two water masses with two different vertical IOP structures gave almost the same water color as seen from above the water. These results highlight the importance of the vertical resolution of IOP measurements near to the surface for constructing a remote sensing algorithm and to assure consistency between AOPs and IOPs (i.e., optical closure). Finally, in terms of $T_{\text {chla }}$ retrieval using a band ratio, the observed NAP enrichment was found to only slightly increase the chlorophyll $a$ estimates.

\subsection{Spectral variation of light absorption by non-algal particles}

Variations in the spectral shape of non-algal particle absorption are usually described using a single parameter, the spectral slope $(S)$ in Eq. (3) applied across the UV-visible domain (e.g., 300-800 nm, Estapa et al., 2012; 380-730 nm, Babin et al., 2003). The average $S^{\mathrm{UVVIS}}$ obtained for the UVvisible domain (300-800 nm) was $0.0085 \mathrm{~nm}^{-1}$ with a coefficient of variation of $17 \%$ and was $0.0094 \mathrm{~nm}^{-1}$ with a coefficient of variation of $11 \%$ for the $380-730 \mathrm{~nm}$ range (as in Babin et al., 2003). This was significantly lower than the values reported by Babin et al. (2003) for coastal waters $\left(0.0123 \mathrm{~nm}^{-1}\right)$, but similar to those reported by Matsuoka et al. (2011) for the Chukchi and western Beaufort seas $\left(0.0104 \mathrm{~nm}^{-1}\right)$. The difference has probably arisen from the nature of the particles, but may also come from the methodological differences. The light amplification factor correction (the so-called beta factor) can have an impact on the spectral slope because it depends upon the optical density (OD; Eq. 2). Here a relationship determined experimentally on natural samples collected in various regions that include both marine and coastal waters was employed. But to increase the 

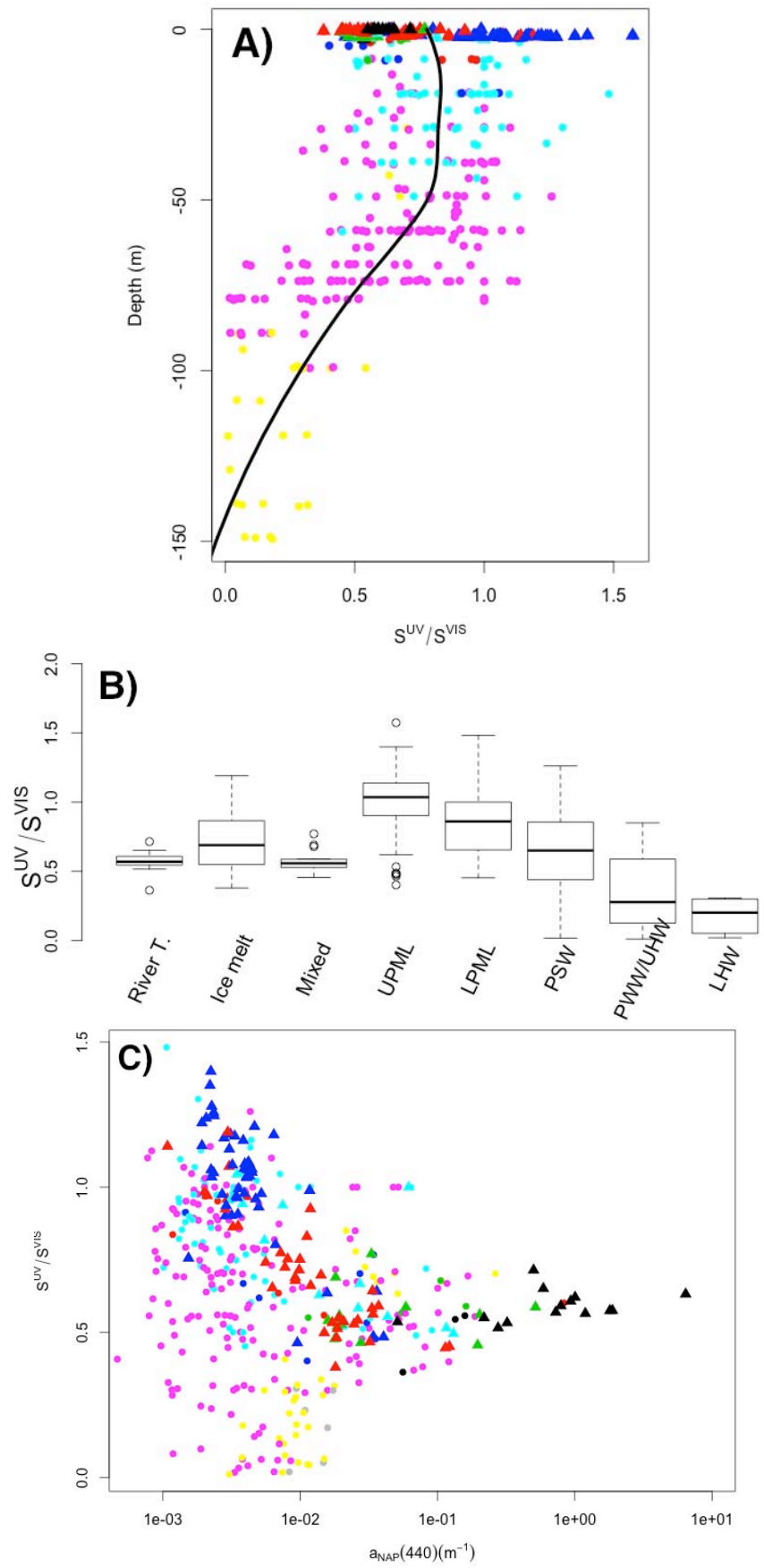

Fig. 10. Variability of the spectral slope ratio between $\mathrm{UV}\left(S^{\mathrm{UV}}\right)$ and visible $\left(S^{\mathrm{VIS}}\right)$ domains. Variation of $S^{\mathrm{UV}}: S^{\mathrm{VIS}}$ with: (A) depth; (B) water masses presented in Fig. 2; and (C) $a_{\mathrm{NAP}}$ at $440 \mathrm{~nm}$.

spectral slope, the decrease in $\beta$ with OD must be steeper than the relationship that we used (Eq. 2). Röttgers and Gehnke (2012) recommended maintaining OD low enough $(<0.1)$ in order to minimize the variation in $\beta$. They also recommended a constant $\beta$ value set at 4.5. Following their recommendations would further decrease the spectral slope.
More work is needed to determine the $\beta$ for measurements made inside an integrating sphere and for the range of natural particle assemblages encountered worldwide, including the Arctic Ocean. Despite the methodological differences, the lower spectral slope encountered in this region could reflect differences in the composition of the particles relative to other coastal waters.

We further examined the spectral shape of NAP in order to gain insights into the vertical variability of these nonalgal particles. We found that the spectral slope of $a_{\text {NAP }}$ calculated in the UV-blue domain (300-500 nm) was not consistently equal to that of the visible domain $(400-700 \mathrm{~nm})$. The slope ratio $S^{\mathrm{UV}}: S^{\mathrm{VIS}}$ varied from 0.01 to 1.6 , with an average value of 0.72 . Interestingly, the vertical variability in $S^{\mathrm{UV}}: S^{\mathrm{VIS}}$ followed a consistently decreasing pattern with depth (Fig. 10a), with values $>0.5$ within the euphotic zone and $<0.5$ at deeper depths. The change in $S^{\mathrm{UV}}: S^{\mathrm{VIS}}$ was mostly driven by the variability in $S^{\mathrm{UV}}$ (not shown). In the Mackenzie River transects and in the mixed surface water masses, $S^{\mathrm{UV}}: S^{\mathrm{VIS}}$ was relatively constant around $\sim 0.5$ (Fig. 10b). Below the surface layer $(0-3 \mathrm{~m})$, changes in the spectral shape of NAP suggested that the non-algal particle composition was changing with depth. We did not observe any significant trends in the POC:SPM ratio $(18 \pm 8 \%)$, which indicates that particulate organic matter contributed to $\sim 50 \%$ of SPM.

High values in $S^{\mathrm{UV}}: S^{\mathrm{VIS}}$ may have been partly due to the presence of phytoplankton associated UV photoprotective MAAs that were not dissolved during methanol extraction of pigments. However, the source of the particulate organic material below the euphotic zone was likely from zooplankton activity (e.g., fecal pellets), while in the euphotic zone it was derived from phytoplankton activity (e.g., cells debris). Thus the change in $S^{\mathrm{UV}}: S^{\mathrm{VIS}}$ probably reflects the bulk composition of detrital POM. Changes in NAP composition could also result, however, from change in the relative proportion of POM and mineral particles at depth. Horizontal transport of particles from the shelf could be significant (Honjo et al., 2010), bringing terrigenous particles at depth due to lateral transport. Unfortunately, we only have a few POC:SPM measurements below $60 \mathrm{~m}$ depth to test this hypothesis.

It is also interesting to note that the variability in $S^{\mathrm{UV}}$ : $S^{\text {VIS }}$ was more important when particle concentrations were relatively low (e.g., $\left.a_{\mathrm{NAP}}(440)<0.01 \mathrm{~m}^{-1}\right)($ Fig. $10 \mathrm{c}) . S^{\mathrm{UV}}$ : $S^{\text {VIS }}$ tended to decrease with increasing $a_{\mathrm{NAP}}(440)$ in the upper and lower PML (cyan and blue) and in the sea ice meltwater (red), but not in the Pacific Summer or Winter Water masses (magenta and yellow). The decreasing trend in $S^{\mathrm{UV}}: S^{\mathrm{VIS}}$ along with increasing $a_{\mathrm{NAP}}(440)$ within the surface waters may have been due to a preferential degradation of visible-absorbing components resulting in a steeper slope of $a_{\mathrm{NAP}}$ in the UV domain in the low concentration range. Since this relationship was observed in the sunlit surface layer, photodegradation of POM may have been responsible for the observed trend. Song et al. (2013) showed 
that photochemical production of carbon monoxide $(\mathrm{CO})$ from POM was significant in the study area during the MALINA program. In addition, the chemical analysis performed on sinking particles during MALINA provided evidence that the material exported out of the euphotic zone in summer was strongly affected by photodegradation processes (Rontani et al., 2012). More work is however needed to test the hypothesis of marine-derived POM photobleaching as a process affecting NAP spectral variability. This would be analogous to the well-known CDOM photobleaching processes (e.g., Del Vecchio and Blough, 2002; Fichot and Benner, 2012). Recently, Estapa et al. (2012b) reported relatively high rates of photodissolution of particles from coastal water (measured as photoproduction of DOC from POM), but could not measure significant change in the particulate absorption due to the dominance of the mineral (i.e., iron) absorption (Estapa et al., 2012a).

\subsection{Spectral absorption budget}

An absorption budget for different wavelengths from the UV to the green part of the spectrum is presented in Fig. 11 using ternary plots that illustrate the relative contribution of each absorbing component to the non-water absorption coefficient. In the UV domain, $330 \mathrm{~nm}$ was chosen because it is where, in the spectrum, photochemical reactions involving CDOM and POM are most important (Bélanger et al., 2006; Xie et al., 2009; Song et al., 2013). Excluding a few samples, the combined absorptions of CDOM and NAP exceeded $90 \%$ at $330 \mathrm{~nm}$ (Fig. 11a). On most occasions, the contribution of CDOM was $80 \%$ of the total light absorption, but NAP could not be neglected, especially within waters influenced by the river where NAP contributed on average to $22 \pm 14 \%$ ( \pm standard deviation) of the UV absorption (see also Fig. 3).

Variability in absorption at $440 \mathrm{~nm}$, where phytoplankton absorption peaks, was still dominated by CDOM $(69.5 \pm 20 \%)$ but both NAP and phytoplankton contributed significantly in some water samples (particularly LPML (cyan), PSW (magenta) and PWW (yellow) water masses; see Figs. 3-6). The largest contribution of phytoplankton to non-water absorption was observed at $490 \mathrm{~nm}(18 \pm 13 \%)$, but was still lower than that of CDOM $(59 \pm 21 \%)$ or NAP $(23 \pm 18 \%)$. In the green part of the spectrum $(555 \mathrm{~nm})$, CDOM still contributed about half the absorption (i.e., $54 \pm 23 \%$ ), while NAP contributed with $35 \pm 22 \%$ of the non-water absorption. These contributions by NAP at 490 and $555 \mathrm{~nm}$ were larger than those reported by Matsuoka et al. $(2007,2009,2011)$ for the Chukchi and Beaufort seas. One reason explaining these results may have been methodological: the null correction in the NIR applied by these authors probably underestimate the contribution of NAP to the non-water absorption and this effect is certainly more important as wavelength gets closer to $750 \mathrm{~nm}$. Nevertheless, our results confirm previous observations made in this region that CDOM is the dominant light absorbing component at all wavelengths and almost everywhere including, in most cases, the sea ice meltwater layer where the overall absorption was low (Ben Mustapha et al., 2012; Bélanger et al., 2008; Matsuoka et al., 2007, 2009).

\subsection{Bio-optical relationships}

Bio-optical relationships between different absorption coefficients and the chlorophyll $a$ concentration are often used in modeling studies addressing remote sensing reflectance (e.g., Wang and Cota, 2003), ocean productivity (e.g., Arrigo et al., 1998), and ocean heating rates (e.g., Morel and Antoine, 1994). Figure 12 presents the relationships obtained from the data collected in the present study. Several remarks can be made about these results.

1. Statistically different $(p<0.01)$ relationships were obtained for surface $(z \geq 3 \mathrm{~m})$ vs. deeper $(z<3 \mathrm{~m})$ waters (triangles vs. dots) for all parameters. The dynamic range observed in the surface water was strongly driven by the river-influenced waters (black and green triangles), resulting in highly significant relationships between the absorption components and $T_{\text {chla }}$.

2. $a_{\text {phy }}$ versus $T_{\text {chla }}$ was within the range of previous relationships reported for the area (Matsuoka et al., 2011; Brunelle et al., 2012) or globally (Bricaud et al., 1998). In surface waters phytoplankton pigments did not exhibit a strong packaging effect (i.e., low $a_{\text {phy }}$ for a given $T_{\text {chla }}$ ) (Fig. 12a).

3. $a_{\mathrm{CDOM}}$ in deeper waters was weakly correlated with $T_{\text {chla }}\left(r^{2}=0.044\right)$ while the surface waters showed a strong correlation $\left(r^{2}=0.82 ; p<0.001\right)$ driven by the river-influenced waters although outliers coming from sea ice meltwater are evident (Fig. 12b).

4. $a_{\text {NAP }}$ vs. $T_{\text {chla }}$ was highly scattered and showed much higher values for a given $T_{\text {chla }}$ (one order of magnitude) relative to the global relationship established by Bricaud et al. (1998) (Fig. 12c). This result confirmed that these waters consistently show a high background in NAP, especially in the surface waters.

5. All three components exhibited significant correlations among each other (not shown), resulting in a moderate $a_{\text {Total }}$ versus $T_{\text {chla }}$ relationship in deeper waters $\left(r^{2}=0.5\right)$ and a relatively strong one for surface waters $\left(r^{2}=0.79 ; p<0.001\right)$ (Fig. 12d).

Non-algal particle absorption at $440 \mathrm{~nm}$ is strongly correlated to SPM (Eq. 5; Fig. 13). Comparison with previous studies (Babin et al., 2003; Bowers and Binding, 2006) indicated that $a_{\mathrm{NAP}}(440)$ may be slightly higher for a given SPM value relative to other coastal waters. The linear regression without intercept (i.e., $a_{\mathrm{NAP}}(440)$ : SPM), for example, yielded a slope 

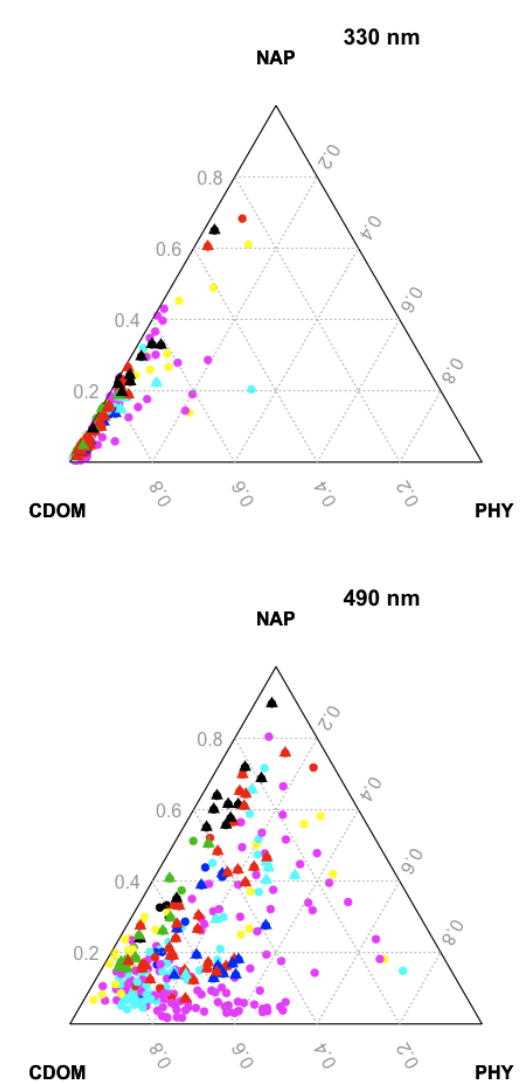
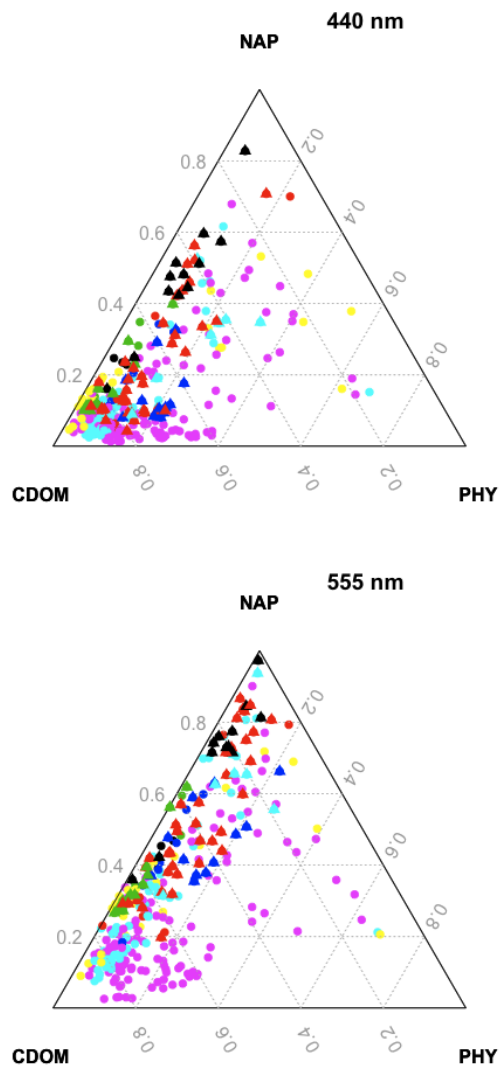

Fig. 11. Ternary plot illustrating the relative contribution of CDOM, phytoplankton, and NAP to absorption, for all samples in this study and different wavelengths. Colors and symbols are the same as in Fig. 2. The relative proportion (within a 01 scale) of a given absorption component $x$ for a given sample was calculated as $x(x+y+z)^{-1}$, where $y$ and $z$ are the two remaining components. The higher the relative contribution of a given component for a given sample is, the closer to the corresponding apex (see component labels) the data point is. The relative contribution of a given absorption component for a given sample can be read on the corresponding axis, where the component label is positioned at the maximum of the scale for that component.

of $0.083 \mathrm{~m}^{2} \mathrm{~g}^{-1}$, which is higher than the slope reported by Babin et al. (2003) and Bowers and Binding (2006). If we applied a null correction in the NIR (e.g., $750 \mathrm{~nm}$ ), we obtained a slope $25 \%$ lower $\left(0.061 \mathrm{~m}^{2} \mathrm{~g}^{-1}\right)$, which is similar to the value reported by Babin et al. (2003) for the Baltic Sea. Figure 13 shows that the difference with previous studies arises mostly at $\mathrm{SPM}>0.5 \mathrm{gL}^{-1}$. These results suggest that the NAP found in the southeastern Beaufort Sea were relatively absorbing, reflecting a significant contribution of organic matter to the bulk composition of the particles.

\section{Conclusions}

During the MALINA field campaign held in August 2009, the sea ice floes were found to cover a large portion of the Mackenzie shelf (Fig. 1). At that time of the year, the sea ice cover, which was essentially composed of multiyear ice, was melting and the meltwater was forming a thin fresh surface layer that appeared nearly ubiquitous in the open waters of the mixed ice-ocean environment during the essentially wind-free and relatively short fetch conditions encountered. Thanks to our sampling strategy for optical properties, this thin layer was documented for the first time, which would have normally been overlooked using a regular ship-based sampling strategy with a classical rosette system. We found evidence that sea ice, and in this case particularly multiyear sea ice, released a significant amount of organic particles upon melting. The enrichment in particles in the nearsurface layer impacted the absorption, vertical diffuse attenuation and reflectance of the incident solar radiation. This is important when IOPs and AOPs are used for an optical closure exercise or remote sensing algorithm development. Based on our results, we recommend that future marine optics fieldwork in the Arctic Ocean include, systematically, the sampling of the near-surface waters (e.g., bucket sampling) in addition to the regular rosette sampling, particularly within mixed ice-ocean environments where surface mixing is weak. Moreover, the thin layer in which particle concentrations are relatively high may be an additional challenge for $R_{\mathrm{rs}}$ estimations from in-water radiometric measurements due to the extrapolation of upwelling radiance from a given depth 


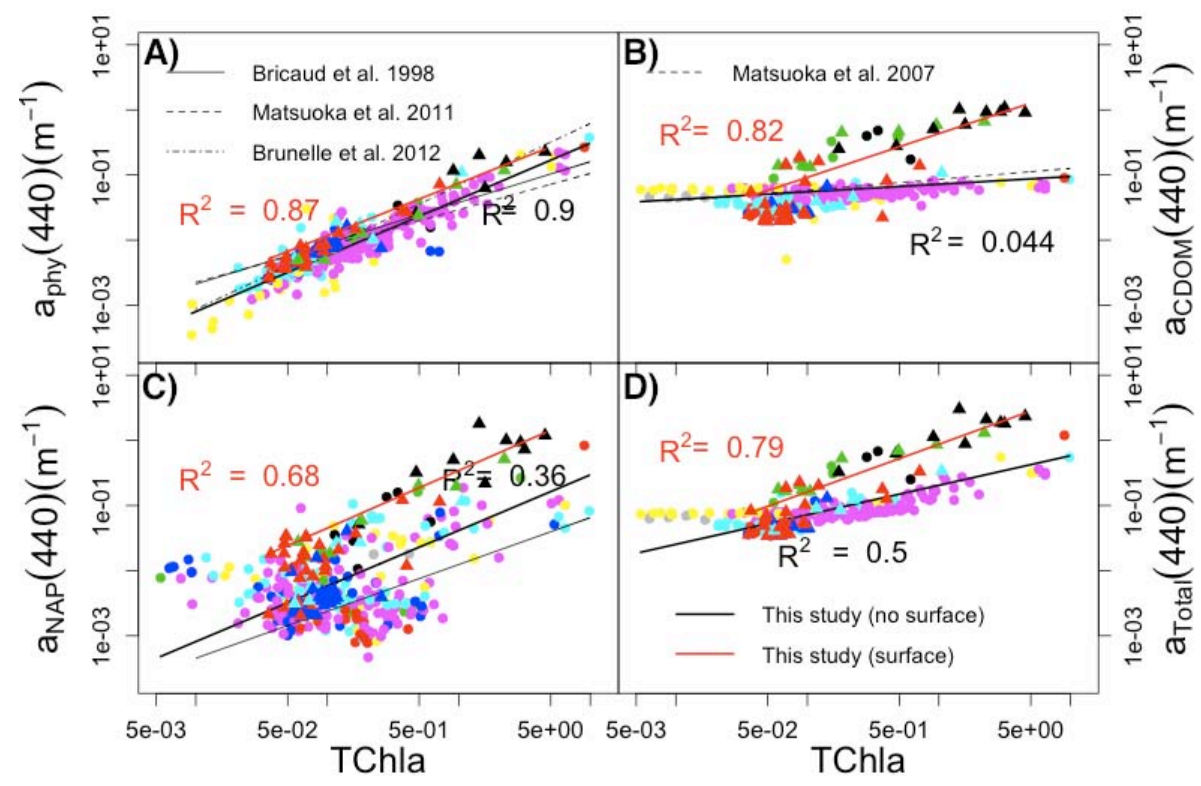

Fig. 12. Relationships between absorbing components and $T_{\text {chla }}$. (A) $a_{\text {phy }}(440)=0.074 \times T_{\text {chla }}^{0.8}\left(r^{2}=0.87 ; N=96\right)$ for surface data and $a_{\text {phy }}(440)=0.042 \times T_{\text {chla }}^{0.86}\left(r^{2}=0.90 ; N=269\right)$ for deeper water; $(\mathbf{B}) a_{\mathrm{CDOM}}(440)=0.43 \times T_{\text {chla }}^{0.67}\left(r^{2}=0.82 ; N=63\right)$ for surface data and $a_{\mathrm{CDOM}}(440)=0.072 \times T_{\text {chla }}^{0.12}\left(r^{2}=0.044 ; N=225\right)$ for deeper water; $(\mathbf{C}) a_{\mathrm{NAP}}(440)=0.34 \times T_{\text {chla }}^{0.89}\left(r^{2}=0.68 ; N=98\right)$ for surface data and $a_{\mathrm{NAP}}(440)=0.041 \times T_{\text {chla }}^{0.85}\left(r^{2}=0.36 ; N=282\right)$ for deeper water; (D) $a_{\text {Total }}(440)=0.87 \times T_{\text {chla }}^{0.73}\left(r^{2}=0.79 ; N=63\right)$ for surface data and $a_{\text {Total }}(440)=0.2 \times T_{\text {chla }}^{0.45}\left(r^{2}=0.5 ; N=224\right)$ for deeper water.

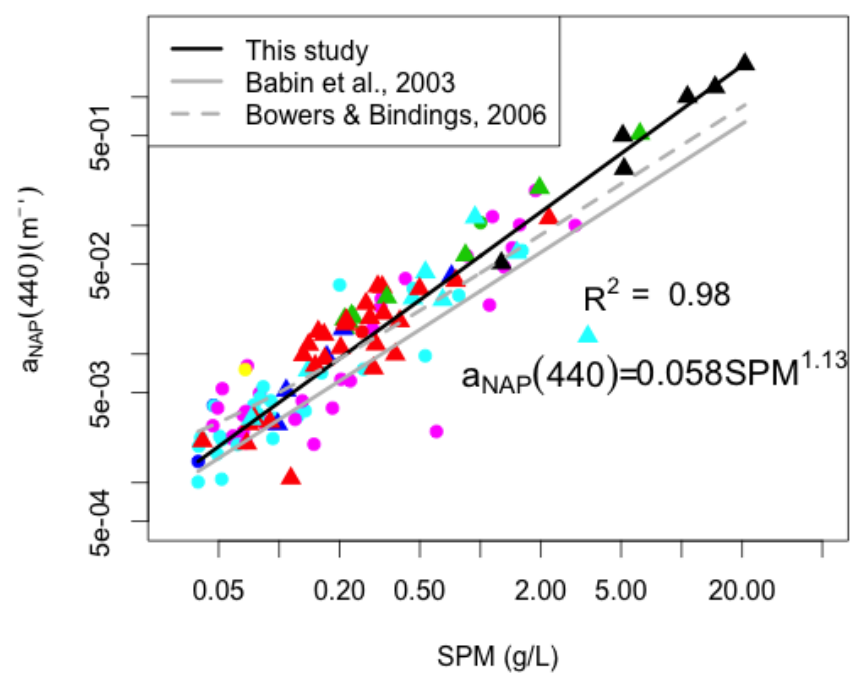

Fig. 13. Relationship between $a_{\mathrm{NAP}}(440)$ and SPM. Note that Babin et al. (2003) and Bowers and Binding (2006) reported the relationship for $443 \mathrm{~nm}$.

$\left(L_{u}(z)\right)$ to $0-$. In general, $L_{u}(z)$ measurements start below $1-2 \mathrm{~m}$ and even deeper. New profiling technology may be better equipped to resolve the near-surface layer, minimizing the errors in $R_{\mathrm{rs}}$ estimation from in-water radiometric measurements (Hooker et al., 2013).
Another interesting finding of our study is the spectral variability in $a_{\text {NAP }}$ with depth. The increase in spectral slope of $a_{\mathrm{NAP}}$ in the UV range in the euphotic zone may indicate that POM photobleaching is efficient enough to affect the spectral shape of NAP. This hypothesis is supported by the findings of Rontani et al. (2012), who showed that sinking particles were strongly photodegraded in the same region. Alternatively, NAP composition may have changed significantly with depth due to other biological processes (e.g., microbial oxidation of POM, production of POM from grazers, etc.). Although it is not clear which process is the most important, the change in $a_{\text {NAP's }}$ spectral shape certainly reflects the nature and origin of the organic particles, as well as their mineral composition (Estapa et al., 2012a, b; Stramski et al., 2007; Babin and Stramski, 2004). We argue that spectral slope analysis of $a_{\text {NAP }}$ can also be used as proxy of the POM composition but studies coupling chemical analysis and optical measurements of particles are needed. For example, spectral slope analysis of $a_{\mathrm{CDOM}}$ is becoming common to study the nature of DOM in the coastal ocean (e.g., Fichot and Benner, 2012; Helms et al., 2008). Generally, our study confirms the importance of CDOM absorption in the Arctic Ocean, and in relative terms even for the very clear sea ice meltwater. However some of the CDOM in the upper surface layer may have been locally formed through oxidation of POM released as the sea ice melted. 


\section{Appendix A}

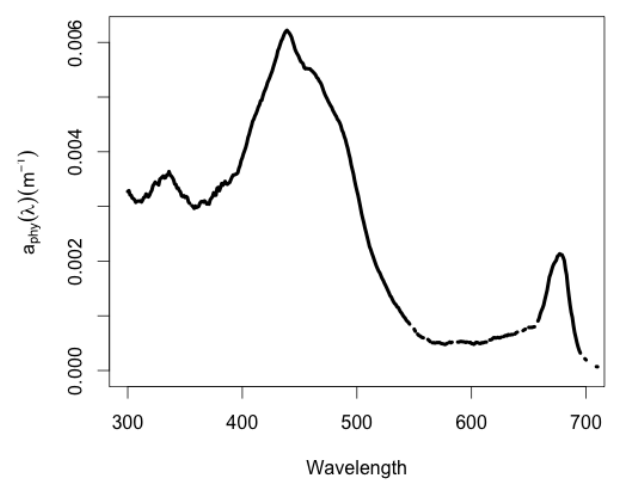

Fig. A1. Median phytoplankton absorption spectrum used in Hydrolight simulations.
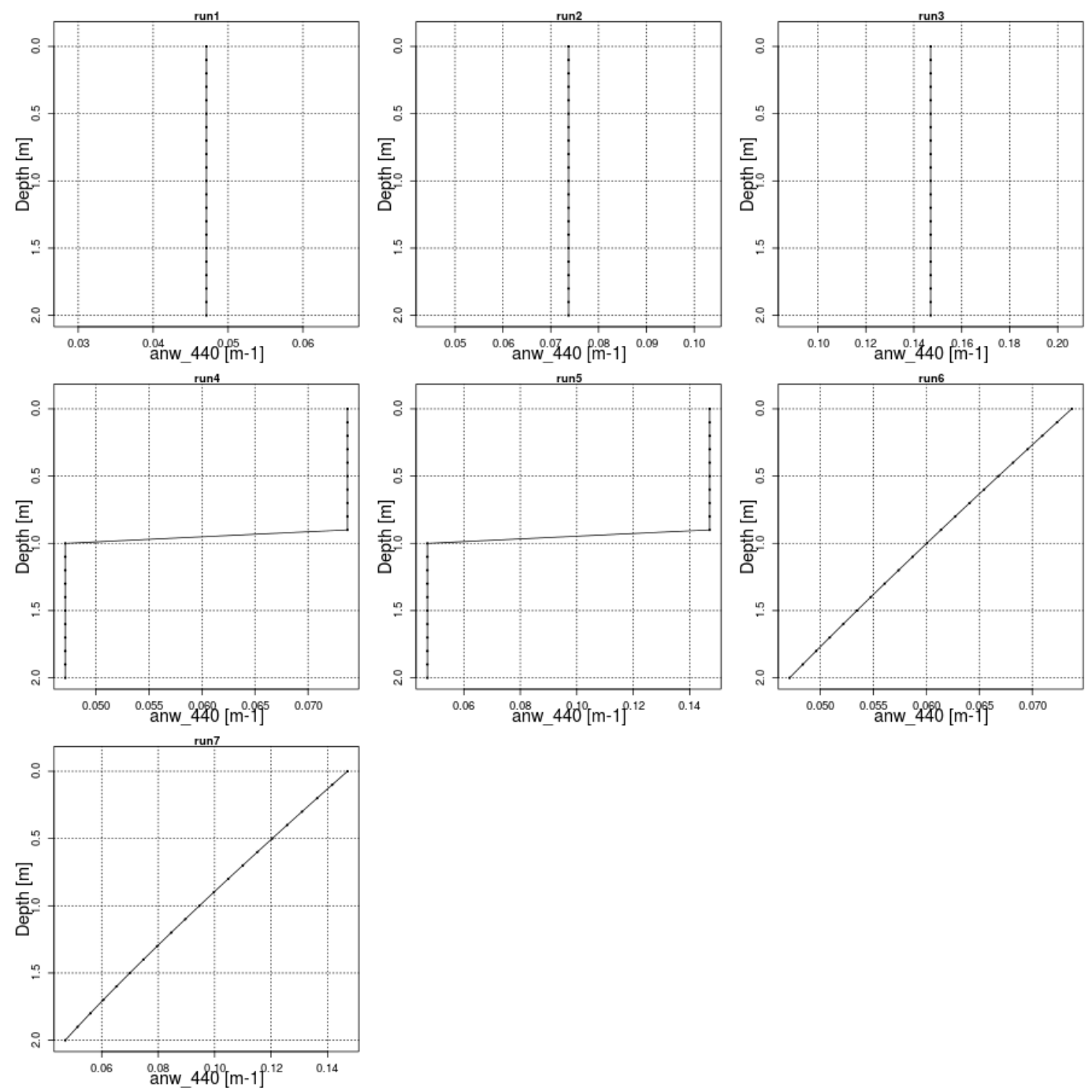

Fig. A2. Vertical profiles of non-water absorption at $440 \mathrm{~nm}$ input in Hydrolight radiative transfer simulations. 

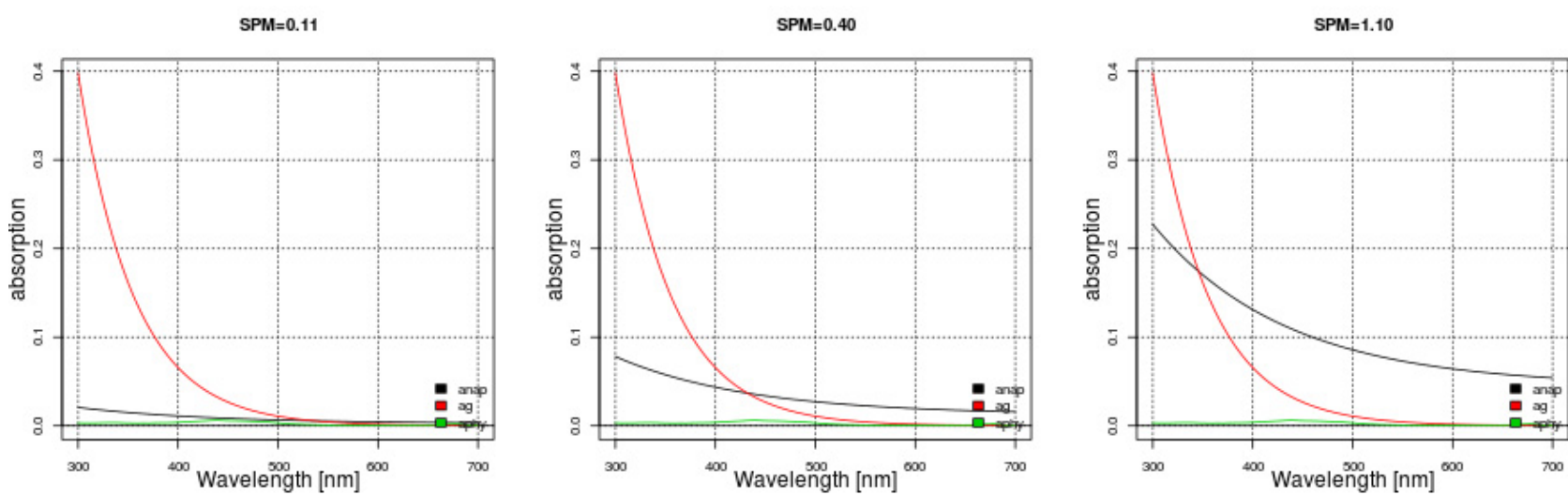

Fig. A3. Spectral variation of the three optical components for the three SPM concentration considered in Hydrolight radiative transfer simulations.
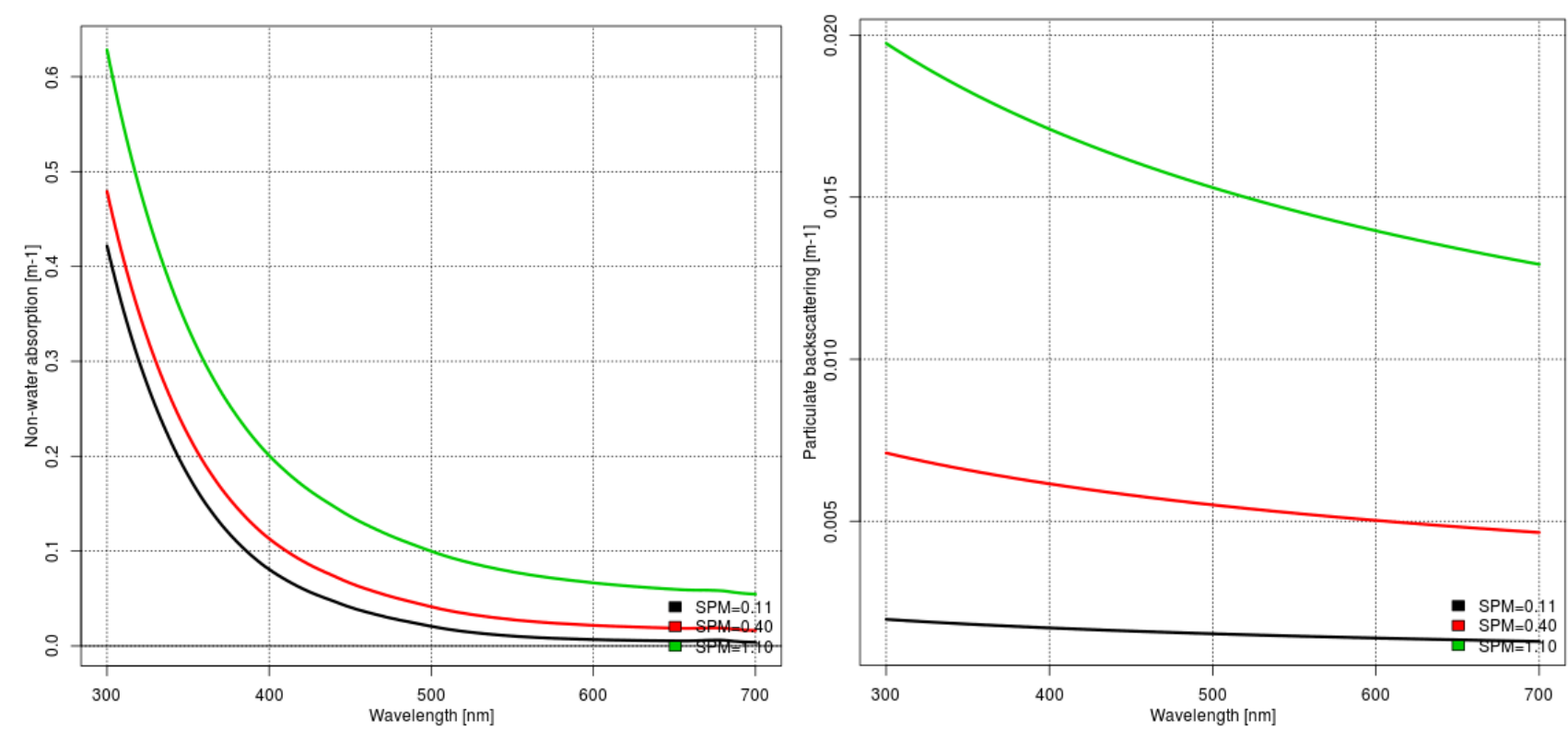

Fig. A4. Spectra of non-water absorption and particles backscattering for the three SPM concentration considered in Hydrolight radiative transfer simulations.

\section{Supplementary material related to this article is available online at http://www.biogeosciences.net/10/ 6433/2013/bg-10-6433-2013-supplement.zip.}

Acknowledgements. We are grateful to the CCG Amundsen crew for their invaluable help and willingness in water sampling, especially from the barge during harsh conditions. We thank two anonymous referees and E. Boss for their constructive comments on the first version of the manuscript. This work was supported by a NSERC Discovery grant and support from ArcticNet awarded to $\mathrm{S}$. Bélanger. The ArcticNet is funded by the program of Networks of Centres of Excellence (NCE) of Canada. This work is a contribution to the MALINA program led by M. Babin. The
MALINA project is funded by the Centre National de la Recherche Scientifique (CNRS) and by the French and European Space Agencies.

Edited by: E. Boss

\section{References}

Arrigo, K. R. and van Dijken, G. L.: Secular trends in Arctic Ocean net primary production, J. Geophys. Res., 116, C09011, doi:10.1029/2011JC007151, 2011.

Arrigo, K. R., Worthen, D., Schnell, A., and Lizotte, M. P.: Primary production in Southern Ocean waters, J. Geophys. Res., 103, 15587-15600, 1998. 
Babin, M. and Stramski, D.: Variations in the mass-specific absorption coefficient of mineral particles suspended in water, Limnol. Oceanogr., 49, 756-767, 2004.

Babin, M., Stramski, D., Ferrari, G. M., Claustre, H., Bricaud, A., Obolensky, G., and Hoepffner, N.: Variations in the light absorption coefficients of phytoplankton, nonalgal particles, and dissolved organic matter in coastal waters around Europe, J. Geophys. Res., 108, 3211, 2003.

Bates, N. R. and Mathis, J. T.: The Arctic Ocean marine carbon cycle: evaluation of air-sea $\mathrm{CO}_{2}$ exchanges, ocean acidification impacts and potential feedbacks, Biogeosciences, 6, 2433-2459, doi:10.5194/bg-6-2433-2009, 2009.

Bélanger, S., Xie, H. X., Krotkov, N., Larouche, P., Vincent, W. F., and Babin, M.: Photomineralization of terrigenous dissolved organic matter in Arctic coastal waters from 1979 to 2003: Interannual variability and implications of climate change, Global Biogeochem. Cy., 20, GB4005, doi:10.1029/2006GB002708, 2006.

Bélanger, S., Babin, M., and Larouche, P.: An empirical ocean color algorithm for estimating the contribution of chromophoric dissolved organic matter to total light absorption in optically complex waters, J. Geophys. Res., 113, C04027, doi:10.1029/2007JC004436, 2008.

Bélanger, S., Babin, M., and Tremblay, J.-E.: Increasing cloudiness in Arctic damps the increase in phytoplankton primary production due to sea ice receding, Biogeosciences, 10, 4087-4101, doi:10.5194/bg-10-4087-2013, 2013.

Ben Mustapha, S., Bélanger, S., and Larouche, P.: Evaluation of ocean color algorithms in the southeastern Beaufort Sea, Canadian Arctic: new parameterization using SeaWiFS, MODIS and MERIS spectral bands, Can. J. Remote Sens. 54, 535-556, 2012.

Bowers, D. G. and Binding, C. E.: The optical properties of mineral suspended particles : a review and synthesis, Estuar. Coast. Shelf S., 67, 219-230, doi:10.1016/j.ecss.2005.11.010, 2006.

Bricaud, A. and Stramski, D.: Spectral absorption coefficients of living phytoplankton and nonalgal biogenous matter: a comparison between the Peru upwelling area and the Sargasso Sea, Limnol. Oceanogr., 35, 562-582, 1990.

Bricaud, A., Morel, A., Babin, M., Allali, K., and Claustre, H.: Variation of light absorption by suspended particles with chlorophyll a concentration in oceanic (case 1) waters: analysis and implications for bio-optical models, J. Geophys. Res., 103, 3103331044, 1998.

Brunelle, C. B., Larouche, P., and Gosselin, M.: Variability of phytoplankton light absorption in Canadian Arctic seas, J. Geophys. Res., 117, C00G17, doi:10.1029/2011JC007345, 2012.

Comiso, J. C., Yang, J., Susumo, H., and Krishfield, R. A.: Detection change in the Arctic using satellite and in situ data, J. Geophys. Res., 108, 3384, doi:10.1029/2002JC001347, 2003.

Del Vecchio, R. and Blough, N. V.: Photobleaching of chromophoric dissolved organic matter in natural waters: kinetics and modeling, Mar. Chem., 78, 231-253, 2002.

Doherty, S. J., Warren, S. G., Grenfell, T. C., Clarke, A. D., and Brandt, R. E.: Light-absorbing impurities in Arctic snow, Atmos. Chem. Phys., 10, 11647-11680, doi:10.5194/acp-1011647-2010, 2010.

Doxaran, D., Ehn, J., Bélanger, S., Matsuoka, A., Hooker, S., and Babin, M.: Optical characterisation of suspended particles in the Mackenzie River plume (Canadian Arctic Ocean) and implica- tions for ocean colour remote sensing, Biogeosciences, 9, 3213 3229, doi:10.5194/bg-9-3213-2012, 2012.

Estapa, M. L., Boss, E., Mayer, L. M., and Roesler, C. S.: Role of iron and organic carbon in mass-specific light absorption by particulate matter from Louisiana coastal waters, Limnol. Oceanogr., 57, 97-112, doi:10.4319/1o.2012.57.1.0097, 2012a.

Estapa, M. L., Mayer, L. M., and Boss, E.: Rate and apparent quantum yield of photodissolution of sedimentary organic matter, Limnol. Oceanogr., 57, 1743-1756, 2012b.

Fichot, C. G. and Benner, R.: The spectral slope coefficient of chromophoric dissolved organic matter (S275-295) as a tracer of terrigenous dissolved organic carbon in riverinfluenced ocean margins, Limnol. Oceanogr., 57, 1453-1466, doi:10.4319/lo.2012.57.5.1453, 2012.

Flanner, M. G., Shell, K. M., Barlage, M., Perovich, D. K., and Tschudi, M. A.: Radiative forcing and albedo feedback from the Northern Hemisphere cryosphere between 1979 and 2008, Nat. Geosci., 4, 151-155, doi:10.1038/ngeo1062, 2011.

Forest, A., Sampei, M., Hattori, H., Makabe, R., Sasaki, H., Fukuchi, M., Wassmann, P., and Fortier, L.: Particulate organic carbon fluxes on the slope of the Mackenzie Shelf (Beaufort Sea): physical and biological forcing of shelf-basin exchanges, J. Mar. Syst., 68, 39-54, doi:10.1016/j.jmarsys.2006.10.008, 2007.

Forest, A.,Babin, M.,Stemmann, L., Picheral, M., Sampei, M., Fortier, L., Gratton, Y., Bélanger, S., Devred, E.,Sahlin, J., Doxaran, D., Joux, F., Ortega-Retuerta, E., Martín, J., Jeffrey, W. H., Gasser, B., Carlos Miquel, J.: Ecosystem function and particle flux dynamics across the Mackenzie Shelf (Beaufort Sea, Arctic Ocean): an integrative analysis of spatial variability and biophysical forcings, Biogeosciences, 10, 2833-2866, doi:10.5194/bg-10-2833-2013, 2013

Giles, K. A., Laxon, S. W., Ridout, A. L., Wingham, D. J., and Bacon, S.: Western Arctic Ocean freshwater storage increased by wind-driven spin-up of the Beaufort Gyre, Nat. Geosci., 5, 194 197, doi:10.1038/ngeo1379, 2012.

Goldenson, N., Doherty, S. J., Bitz, C. M., Holland, M. M., Light, B., and Conley, A. J.: Arctic climate response to forcing from light-absorbing particles in snow and sea ice in CESM, Atmos. Chem. Phys., 12, 7903-7920, doi:10.5194/acp-12-79032012, 2012.

Helms, J. R., Stubbins, A., Ritchie, J. D., Minor, E. C., Kieber, D. J., and Mopper, K.: Absorption spectral slopes and slope ratios as indicators of molecular weight, source, and photobleaching of chromophoric dissolved organic matter, Limnol. Oceanogr., 53, 955-969, doi:10.4319/lo.2008.53.3.0955, 2008.

Hill, V. J.: Impacts of chromophoric dissolved organic material on surface ocean heating in the Chukchi Sea, J. Geophys. Res., 113, C07024, doi:10.1029/2007JC004119, 2008.

Hooker, S. B., Van Heukelem, L., Thomas, C. S., Claustre, H., Ras, J., Barlow, R., Sessions, H., Schluter, L., Perl, J., Trees, C., Stuart, V., Head, H., Clementson, L., Fishwick, J., Llewellyn, C., and Aiken, J.: The second SeaWiFS HPLC Analysis RoundRobin Experiment (SeaHARRE-2), in: Technical Memorandum NASA/TM-2005-212787, NASA Goddard Space Flight Center, Greenbelt, MD, 112 pp., 2005.

Hooker, S. B., Morrow, J. H., and Matsuoka, A.: Apparent optical properties of the Canadian Beaufort Sea - Part 2: The $1 \%$ and $1 \mathrm{~cm}$ perspective in deriving and validating AOP data products, 
Biogeosciences, 10, 4511-4527, doi:10.5194/bg-10-4511-2013, 2013.

Kishino, M., Takahashi, M., Okami, N., and Ichimura, S.: Estimation of the spectral absorption coefficients of phytoplankton in the sea, Bull. Mar. Sci., 37, 634-642, 1985.

Li, W. K. W., McLaughlin, F. A., Lovejoy, C., and Carmack, E. C.: Smallest algae thrive as the Arctic Ocean freshens, Science, 326, 539, doi:10.1126/science.1179798, 2009.

Matsuoka, A., Huot, Y., Shimada, K., Saitoh, S.-I., and Babin, M.: Bio-optical characteristics of the western Arctic Ocean: implications for ocean color algorithms, Can. J. Remote Sens., 33, 503-518, 2007.

Matsuoka, A., Larouche, P., Poulin, M., Vincent, W., and Hattori, H.: Phytoplankton community adaptation to changing light levels in the southern Beaufort Sea, Canadian Arctic, Estuar. Coast. Shelf S., 82, 537-546, doi:10.1016/j.ecss.2009.02.024, 2009.

Matsuoka, A., Hill, V., Huot, Y., Babin, M., and Bricaud, A.: Seasonal variability in the light absorption properties of western Arctic waters: parameterization of the individual components of absorption for ocean color applications, J. Geophys. Res., 116, 115, doi:10.1029/2009JC005594, 2011.

Matsuoka, A., Bricaud, A., Benner, R., Para, J., Sempéré, R., Prieur, L., Bélanger, S., and Babin, M.: Tracing the transport of colored dissolved organic matter in water masses of the Southern Beaufort Sea: relationship with hydrographic characteristics, Biogeosciences, 9, 925-940, doi:10.5194/bg-9-925-2012, 2012.

Mobley, C. D.: Light and water: Radiative Transfer in Natural Waters, 1st edn., Academic Press, San Diego, California, 1994.

Mobley, C. D., Sundman, L. K., and Boss, E.: Phase function effects on oceanic light fields, Appl. Optics, 41, 1035-1050, 2002.

Mopper, K. and Keiber, D. J.: Photochemistry and the Cycling of Carbon, Sulfur, Nitrogen and Phosphorus, in: Biogeochemistry of marine dissolved organic matter, 1st edn., edited by Hansell, D. A. and Carlson, C. A., Academic Press, San Diego, 455-507, 2002.

Morel, A.: Available, usable, and stored radiant enerphy in relation to marine photosynthesis, Deep-Sea Res., 25, 673-688, 1978.

Morel, A.: Light and marine photosynthesis: a spectral model with geochemical and climatological implications, Prog. Oceanogr., 26, 263-306, 1991

Morel, A. and Antoine, D.: Heating rate within the upper ocean in relation to its bio-optical state, J. Phys. Oceanogr., 24, 1652 1665,1994

O’Brien, M. C., MacDonald, R. W., Melling, H., and Iseki, K.: Particles fluxes and geochemistry on the Canadian Beaufort Shelf: implications for sediment transport and deposition, Cont. Shelf Res., 26, 41-81, 2006.

Orellana, M. V., Matrai, P. A., Leck, C., Rauschenberg, C. D., Lee, A. M., and Coz, E.: Marine microgels as a source of cloud condensation nuclei in the high Arctic., Proc. Natl. Acad. Sci., 108, 13612-13617, doi:10.1073/pnas.1102457108, 2011.

Palm, S. P., Strey, S. T., Spinhirne, J., and Markus, T.: Influence of Arctic sea ice extent on polar cloud fraction and vertical structure and implications for regional climate, J. Geophys. Res., 115, 1-9, doi:10.1029/2010JD013900, 2010.

Pegau, W. S.: Inherent optical properties of the central Arctic surface waters, J. Geophys. Res., 107, doi:10.1029/2000JC000382, 2002 .
Perovich, D. K., Light, B., Eicken, H., Jones, K. F., Runciman, K., and Nghiem, S. V.: Increasing solar heating of the Arctic Ocean and adjacent seas, 1979-2005: attribution and role in the ice-albedo feedback, Geophys. Res. Lett., 34, L19505, doi:10.1029/2007GL031480, 2007.

Ras, J., Claustre, H., and Uitz, J.: Spatial variability of phytoplankton pigment distributions in the Subtropical South Pacific Ocean: comparison between in situ and predicted data, Biogeosciences, 5, 353-369, doi:10.5194/bg-5-353-2008, 2008

Rontani, J.-F., Charriere, B., Forest, A., Heussner, S., Vaultier, F., Petit, M., Delsaut, N., Fortier, L., and Sempéré, R.: Intense photooxidative degradation of planktonic and bacterial lipids in sinking particles collected with sediment traps across the Canadian Beaufort Shelf (Arctic Ocean), Biogeosciences, 9, 4787-4802, doi:10.5194/bg-9-4787-2012, 2012.

Röttgers, R. and Gehnke, S.: Measurement of light absorption by aquatic particles: improvement of the quantitative filter technique by use of an integrating sphere approach, Appl. Optics, 51, 13361351, 2012.

Song, G., Xie, H., Bélanger, S., Leymarie, E., and Babin, M.: Spectrally resolved efficiencies of carbon monoxide (CO) photoproduction in the Western Canadian Arctic: particles versus solutes, Biogeosciences, 10, 3731-3748, doi:10.5194/bg-10-3731-2013, 2013.

Stramski, D., Babin, M., and Wozniak, S.: Variations in the optical properties of terrigenous mineral-rich particulate matter suspended in seawater, Limnol. Oceanogr., 52, 2418-2433, 2007.

Stroeve, J. C., Serreze, M. C., Holland, M. M., Kay, J. E., Malanik, J., and Barrett, A. P.: The Arctics rapidly shrinking sea ice cover: a research synthesis, Clim. Change, 110, 1005-1027, doi:10.1007/s10584-011-0101-1, 2012.

Thomas, D. N., Papadimitriou, S., and Michel, C.: Biogeochemistry of sea ice, in: Sea Ice, edited by: Thomas, D. N. and Dieckmann, G. S., 425-466, Wiley-Blac edn., 2010.

Tremblay, J.-E. and Gagnon, J.: The effects of irradiance and nutrient supply on the productivity of Arctic waters: a perspective on climate change, in: Influence of climate chang on changing Arctic and sub-arctic conditions, edited by: Nihoul, J. C. J. and Kostianoy, A. G., 73-89, Springer, 2009.

Tremblay, J.-E., Bélanger, S., Barber, D. G., Asplin, M., Martin, J., Darnis, G., Fortier, L., Gratton, Y., Link, H., Archambault, P., Sallon, A., Michel, C., Williams, W. G., Philippe, B., and Gosselin, M.: Climate forcing multiplies biological productivity in the coastal Arctic Ocean, Geophys. Res. Lett., 38, L18604, doi:10.1029/2011GL048825, 2011.

Van Der Linde, D.: Protocol for determination of total suspended matter in oceans and coastal zones, Joint Res. Cent., Brussels, Tech. Note I.98.182, 1998.

Van Heukelem, L. and Thomas, C. S.: Computer-assisted highperformance liquid chromatography method development with applications to the isolation and analysis of phytoplankton pigments, J. Chromatogr. A, 910, 31-49, 2001.

Wang, J. and Cota, G. F.: Remote-sensing reflectance in the Beaufort and Chukchi seas: observations and models, Appl. Optics, 42, 2754-2765, 2003.

Williams, W. G. and Carmack, E. C.: Combined effect of wind-forcing and isobath divergence on upwelling at Cape Bathurst, Beaufort Sea, J. Mar. Syst., 66, 645-663, doi:10.1357/002224008787536808, 2008 
Xie, H. and Zafiriou, O. C.: Evidence for significant photochemical production of carbon monoxide by particles in coastal and oligotrophic marine waters, Geophys. Res. Lett., 36, L23606, doi:10.1029/2009GL041158, 2009.
Xie, H. X., Bélanger, S., Demers, S., Vincent, W. F., and Papakyriakou, T.: Photobiogeochemical cycling of carbon monoxide in the southeastern Beaufort Sea in spring and autumn, Limnol. Oceanogr., 54, 234-249, 2009. 